\title{
Temperature-mediated tribological characteristics of 40CrNiMoA steel and Inconel 718 alloy during sliding against $\mathrm{Si}_{3} \mathrm{~N}_{4}$ counterparts
}

\author{
Liuyang BAI ${ }^{1,2}$, Shanhong WAN ${ }^{1,2, *}$, Gewen $\mathbf{Y I}^{1,2, *}$, Yu SHAN ${ }^{1}$, Sang The PHAM ${ }^{3}$, Anh Kiet TIEU ${ }^{3}$, Yan LI $^{4}$, \\ Rendong WANG ${ }^{5}$ \\ ${ }^{1}$ State Key Laboratory of Solid Lubrication, Lanzhou Institute of Chemical Physics, Chinese Academy of Sciences, Lanzhou \\ 730000, China \\ ${ }^{2}$ Center of Materials Science and Opto-Electronics Engineering, University of Chinese Academy of Sciences, Beijing 100049, China \\ ${ }^{3}$ Faculty of Engineering and Information Sciences, University of Wollongong, Wollongong 2522, Australia \\ ${ }^{4}$ State Key Laboratory of Metal Materials for Marine Equipment and Application, Anshan 114009, China \\ ${ }^{5}$ Ansteel Iron \& Steel Research Institute, Anshan 114009, China
}

Received: 10 March 2020 / Revised: 30 July 2020 / Accepted: 23 September 2020

(C) The author(s) 2020 .

\begin{abstract}
A comparative evaluation of the friction and wear behaviors of $40 \mathrm{CrNiMoA}$ steel and Inconel 718 alloy sliding against $\mathrm{Si}_{3} \mathrm{~N}_{4}$ counterparts was conducted over a large temperature range from room temperature (RT) to $800{ }^{\circ} \mathrm{C}$. The temperature-dependent tribological properties associated with the resulting chemical mitigation and structural adaptation of the solid sliding surface were clarified by surface/interface characterizations. The results revealed desirable performance in reducing friction and wear at elevated temperatures, which was associated with the resulting oxide composite film's adaptive lubricating capability, whereas severe abrasive wear occurred at room/ambient temperatures. The oxidative-abrasive differentials for the two alloys were further discussed by considering the combined effect of temperature and stressed-shearing conditions.
\end{abstract}

Keywords: steel alloys; high-temperature tribology; wear and friction; oxidation; surface/interface chemistry

\section{Introduction}

High-temperature tribological characteristics of high-strength alloyed materials have been studied considerably in aerospace, power generation, material processing, and metalworking industries. A series of problems occur simultaneously between frictional contacts, such as abrasion, plastic deformation, and fatigue [1]. During high-temperature friction, oxides preferentially form on the worn surface [2], and their thicknesses play a pivotal role in tribological performance [3]. If the tribochemically grown oxide layer behaves effectively, it can deliver the desired lubricity between the rubbing contacts at elevated temperatures [4]. However, not all in situ grown oxide layers perform favorably. Temperature has a significant effect on tribological varieties of alloyed materials [5,6]. Thus, attempts to comprehend the tribological capabilities and underlying mechanism of alloyed materials in terms of microstructure transition and composition migration across the sliding surface/interface are still ongoing.

At room/ambient temperatures, the frictional

* Corresponding authors: Shanhong WAN, E-mail: shwan@licp.cas.cn; Gewen YI, E-mail: gwyi@licp.cas.cn 
surface suffers dominant abrasion [1,7]. Because the operational temperature is not sufficiently high to grind the wear debris and thus a continuous protection layer is not present, the abrasion and subsequent oxidation interact with each other, thereby leading to severe wear and unexpected abrading of the three body [8]. The applied force and total sliding distance are the predominant factors in the wear process, during which the kinetics of oxidation at the sliding surface, other than temperature, contribute significantly to the acceleration of wear.

A severe-to-moderate wear transition emerges between the rubbing contact as the temperature exceeds a critical temperature, which is attributed to a compliant oxide layer [9]. This oxide layer is often termed "glaze", which evolves from the oxide debris by the tribo-sintering process. This layer also displays a composite feature consisting amorphous and nanocrystalline components. Such structural assembly enables accommodation of the interfacial stresses [10], which is considered to be the major plasticity activator that renders desirable ductility when exposed to harsh temperatures. However, the tribological capability of this oxide layer is further associated with the reduction of the mechanical strengths of materials at elevated temperatures [11], variations in surface conditions and adhesion due to oxidation and diffusion [12], phase change, and composition change [13], which inherently depends on the temperature.

Both 40CrNiMoA steel and Inconel 718 alloy have superior strengths and toughnesses for equipment manufacturing and aerospace industries [14, 15]. They have been widely applied as high-temperature substrates for coating deposition. However, the capabilities to withstand friction and wear of the two alloys themselves have not been comprehensively investigated for a wide range of temperatures. In particular, knowledge of the tribological discrepancy between nickel-based (Inconel 718 alloy) and iron-based (40CrNiMoA steel) alloys at elevated temperatures is still a little far from the industrial demand in machinery components, which often require working in harsh temperature conditions. In this study, the tribological dependencies of these two alloyed materials are investigated comparatively during sliding against a ceramic $\mathrm{Si}_{3} \mathrm{~N}_{4}$ counterpart at different temperatures. In addition to the connection between temperature and the resulting tribological properties, the surfaces and interface of the worn $40 \mathrm{CrNiMoA}$ steel and Inconel 718 alloy are analyzed in terms of the resulting oxide layer to clarify the wearing mechanism and frictional evolution. The findings of this study will be potentially instructive for the manufacturing of high-strength alloys and the availability of ceramic silicon nitride as a manufacturing tool in harsh hot air environments.

\section{Experimental}

\subsection{Applied materials}

Two different alloys were investigated in this study: 40CrNiMoA steel and Inconel 718 alloy. Commercial 40CrNiMoA steel (AISI 4340) was purchased from Jiangyin Xingcheng Special Steel Works Co. Ltd., while the superalloy Inconel 718 was purchased from Suzhou Feiyue Precision Machinery Co. Ltd. Table 1 shows the chemical composition of 40CrNiMoA steel and Inconel 718 superalloy. Predominantly Fe, along with all other alloying elements, make up 40CrNiMoA high-strength steel, while the three main components of $\mathrm{Ni}, \mathrm{Fe}$, and $\mathrm{Cr}$ are included within the as-received Inconel 718 alloy.

Table 1 Chemical compositions of 40CrNiMoA steel and Inconel 718 superalloy (wt\%).

\begin{tabular}{|c|c|c|c|c|c|c|c|c|c|c|}
\hline & $\mathrm{C}$ & $\mathrm{O}$ & Mo & $\mathrm{Al}$ & $\mathrm{Nb}$ & $\mathrm{Mn}$ & $\mathrm{Ti}$ & $\mathrm{Cr}$ & $\mathrm{Fe}$ & $\mathrm{Ni}$ \\
\hline 40CrNiMoA & 2.53 & 0.77 & 0.05 & - & - & 0.37 & - & 0.45 & 95.12 & 0.71 \\
\hline Inconel 718 & 2.31 & 0.62 & 1.25 & 0.29 & 2.15 & - & 0.51 & 17.28 & 15.58 & 60.01 \\
\hline
\end{tabular}

Note: - indicates that it is not detected. 
Figure 1 displays the metallurgical phase of the two alloyed materials with the assistance of the spot energy-dispersive spectroscopy (EDS). 40CrNiMoA steel consists of tempered martensite, retained austenite, and some precipitated granular carbides (spot 1 in Fig. 1(b) and Fig. 1(c)). It is identifiable that ultra-fine carbides are distributed homogeneously within the lath-shaped martensite matrix. As shown in Fig. 1(d) and spot 4 in Fig. 1(e), Inconel 718 alloy demonstrates a net-like convex structure with a dominant carbide ( $\mathrm{Nb}$ and $\mathrm{Mo}$ ) composition along the grain boundary [16] within the austenitic matrix, while such needle-like $\delta$ phases are invisible. In addition, the $\gamma^{\prime \prime}\left(\mathrm{Ni}_{3} \mathrm{Nb}\right)$ precipitate can be distinguished [17] according to the EDS in Fig. 1(f) because of the chemical affinities of $\mathrm{Ni}$ and $\mathrm{Nb}$.

Disk specimens for the friction and wear testing had dimensions of $\Phi 24 \mathrm{~mm} \times 8 \mathrm{~mm}$, which were cut from 40CrNiMoA steel and Inconel 718 alloy

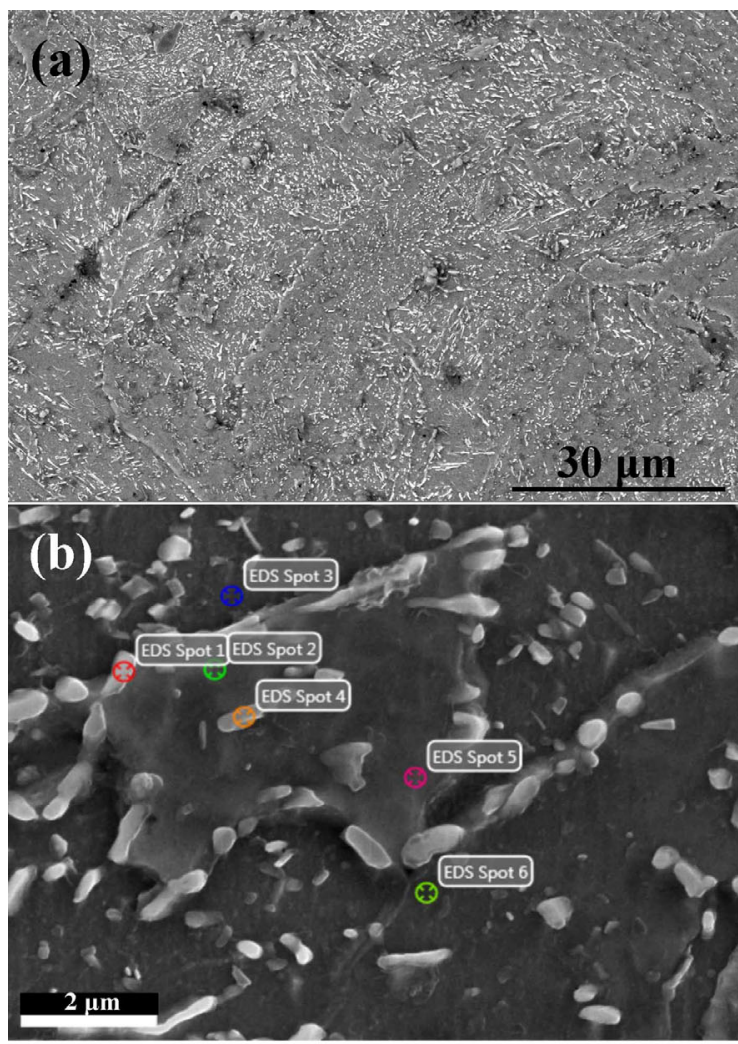

(d)
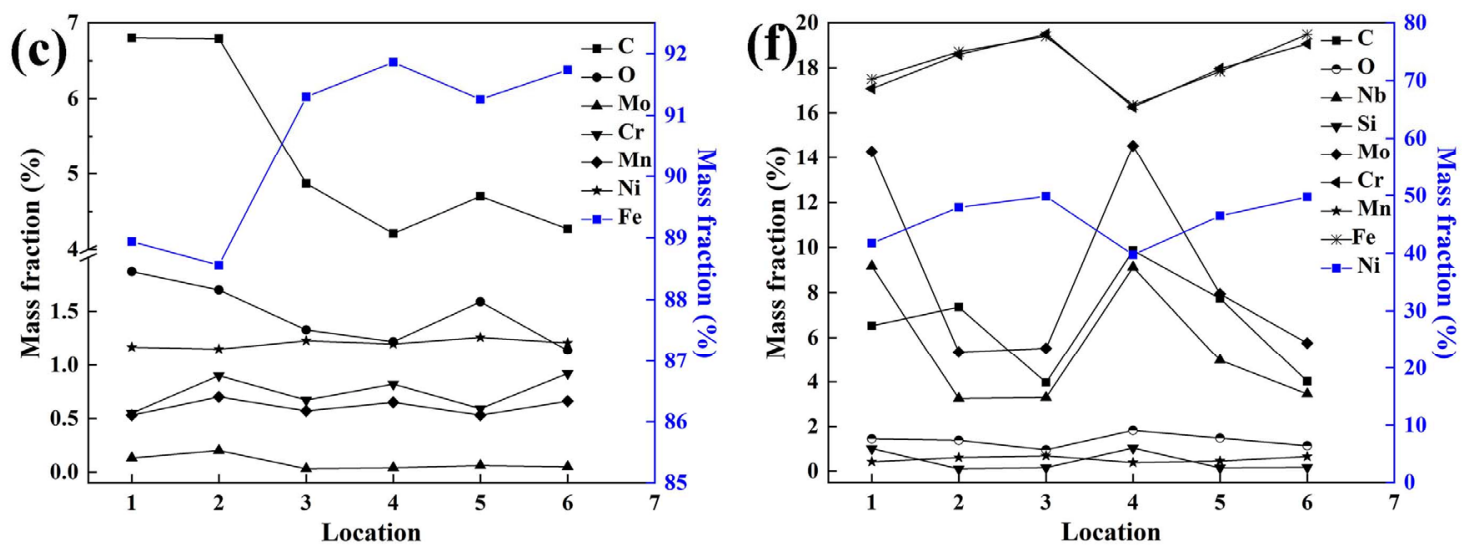

Fig. 1 Microstructure and metallurgical composition analyses of the alloyed materials. (a-c) $40 \mathrm{CrNiMoA}$ steel, and (d-f) Inconel 718 alloy. 
bars. All the disk specimens were machined to a surface roughness, $\mathrm{Ra}$, of approximately $0.02 \mu \mathrm{m}$. Because $\mathrm{Si}_{3} \mathrm{~N}_{4}$ has excellent mechanical strength and high thermal stability without any deformation at $800{ }^{\circ} \mathrm{C}$ [18], $\mathrm{Si}_{3} \mathrm{~N}_{4}(\Phi 6 \mathrm{~mm}, \mathrm{Ra} 0.02 \mu \mathrm{m})$ was selected as the counterpart material for this work and was purchased from Shanghai Unite Technology Co. Ltd. The $\mathrm{Si}_{3} \mathrm{~N}_{4}$ ball had a chemical composition (wt $\%$ ) consisting of $\mathrm{N} 41.27 \%$, O 19.57\%, Al 2.17\%, Y 1.57\%, Nb 13.5\%, Ti 0.22\%, and $\mathrm{Si}$ in balance. Prior to tribological testing, the disk and ball were ultrasonically cleaned for $15 \mathrm{~min}$ in a solution of acetone, and then dried in hot air.

\subsection{Mechanical and tribological evaluation}

The microhardness of the two alloys was measured using an MH-5-VM microhardness tester, which was manufactured by Shanghai Hengyi Science and Technology Co. Ltd., with a Vickers pyramid-shaped diamond indenter with an angle of $136^{\circ}$ between opposite faces. At least 11 microhardness values were taken from each sample under different loadings, with a dwell time of $5 \mathrm{~s}$. Scratch tests were carried out using an RST ${ }^{3}$ scratch machine (Anton Paar, Switzerland) using a conical diamond indenter with a radius of $200 \mu \mathrm{m}$ and cone angle of $120^{\circ}$. Scratch testing was performed with a linearly increasing load from 0 to $50 \mathrm{~N}$ at a normal loading speed of $98 \mathrm{~N} / \mathrm{min}$ and a scratch length of $5 \mathrm{~mm}$.

The tribological performances of $40 \mathrm{CrNiMoA}$ steel and Inconel 718 alloy sliding against $\mathrm{Si}_{3} \mathrm{~N}_{4}$ were tested using a high-temperature ball-on-disk tribometer (UMT-3, Bruker Corp, USA) in air with a relative humidity of $20 \% \pm 5 \%$ at $25{ }^{\circ} \mathrm{C}$. The upper specimen was a $\mathrm{Si}_{3} \mathrm{~N}_{4}$ ball, while the bottom disk specimen was composed of $40 \mathrm{CrNiMoA}$ steel or Inconel 718 alloy. All rotation tests were carried out at a sliding speed of $0.104 \mathrm{~m} / \mathrm{s}$ (200 rotations/min), an applied load of $10 \mathrm{~N}$, a wear track radius of $5 \mathrm{~mm}$, and a duration of $1 \mathrm{~h}$. The testing temperatures were room temperature $\left(\mathrm{RT}, 25{ }^{\circ} \mathrm{C}\right)$, 200, 400, 600, and $800{ }^{\circ} \mathrm{C}$. Before the frictional test started, the tribosystem was heated up to the target temperature with a heating rate of $10{ }^{\circ} \mathrm{C} / \mathrm{min}$. In order to ensure the reproducibility of the data, each frictional test was repeated at least twice.

The friction coefficient of the specimen was automatically recorded by a computer attached to the UMT-3, and the wear rate, in $\mathrm{mm}^{3} /(\mathrm{N} \cdot \mathrm{m})$, was calculated according to Eq. (1),

$$
\omega=\Delta V /(F \cdot S)
$$

where $\Delta V$ is the wear volume loss in $\mathrm{mm}^{3}, S$ is the sliding distance in $\mathrm{m}$, and $F$ is the load in $\mathrm{N}$. The volume loss $\Delta V_{1}$ of the sample was acquired by Eq. (2),

$$
\Delta V_{1}=2 \pi R S
$$

where $R$ is the wear radius of the sample, and $S$ is the cross-sectional area of the wear track. The wear volume $\Delta V_{2}$ of the counterpart was obtained by a geometric method of measuring the wear scar diameter of the ball with a confocal laser scanning microscope (Olympus BX53, Japan). $\Delta V_{2}$ was calculated according to Eq. (3) [19]:

$$
\Delta V_{2}=\frac{\pi}{12}\left(R-\sqrt{R^{2}-\frac{D^{2}}{4}}\right)\left(D^{2}+4 R^{2}-4 R \sqrt{R^{2}-\frac{D^{2}}{4}}\right)
$$

where $R$ is the radius of the ball and $D$ is the diameter of the worn scar.

\subsection{Characterization}

The surface roughness values of all disk specimens were measured using a type 2206 surface roughness instrument manufactured by Harbin Measuring Cutting Tool Group Co. Ltd. A surface profiler (KLA Tencor D-100, USA) was used to evaluate the wear loss by scanning the wear track on the disk. The metallurgical identification between 40CrNiMoA steel and Inconel 718 alloy was performed by field emission scanning electron microscopy (FESEM; FEI Apreo S, USA). The quantitative analyses of the elements were performed by EDS with backscattered electron imaging (BSE) at $20 \mathrm{kV}$. Prior to the metallurgical analysis, 40CrNiMoA steel was etched with nital for $50 \mathrm{~s}$ ( $4 \% \mathrm{HNO}_{3}$ in alcohol solution), and the Inconel 718 alloy was etched with a special reagent (5 $\mathrm{g} \mathrm{CuCl}_{2}, 100 \mathrm{~mL} \mathrm{HCl}$, and $100 \mathrm{~mL}$ anhydrous alcohol). The damaged surfaces and interface at the central zone of the wear track were further analyzed by scanning electron microscopy (SEM)/EDS, where the thickness of the tribolayer could be determined from the cross-sectional-view image. Using BSE imaging, light elements were 
depicted as darker than heavy elements; for example, the iron-based material appears lighter, and the abrasive particles of oxide appear darker [20]. The representative compositions of worn and unworn surfaces were analyzed using a Raman spectrometer (LabRAM HR Evolution, HORIBA Jobin Yvon S.A.S. France) with a solid-state laser having an excitation wavelength of $532 \mathrm{~nm}$ in a window from 100 to $1,800 \mathrm{~cm}^{-1}$. The Raman data were collected continuously using a $30 \mathrm{~s}$ exposure time with two accumulations.

\section{Results and discussion}

\subsection{Mechanical evaluation of the two alloys}

The average microhardness values of $40 \mathrm{CrNiMoA}$ steel and Inconel 718 alloy are given in Table 2. Because the dominant $\gamma^{\prime}\left(\mathrm{Ni}_{3} \mathrm{Nb}\right)$ and $\gamma^{\prime}\left(\mathrm{Ni}_{3}(\mathrm{Al}, \mathrm{Ti})\right)$ phases, along with other alloying elements such as $\mathrm{Nb}, \mathrm{Al}$, and $\mathrm{Ti}$, render a superior strengthening effect, Inconel 718 alloy has a hardness twice as

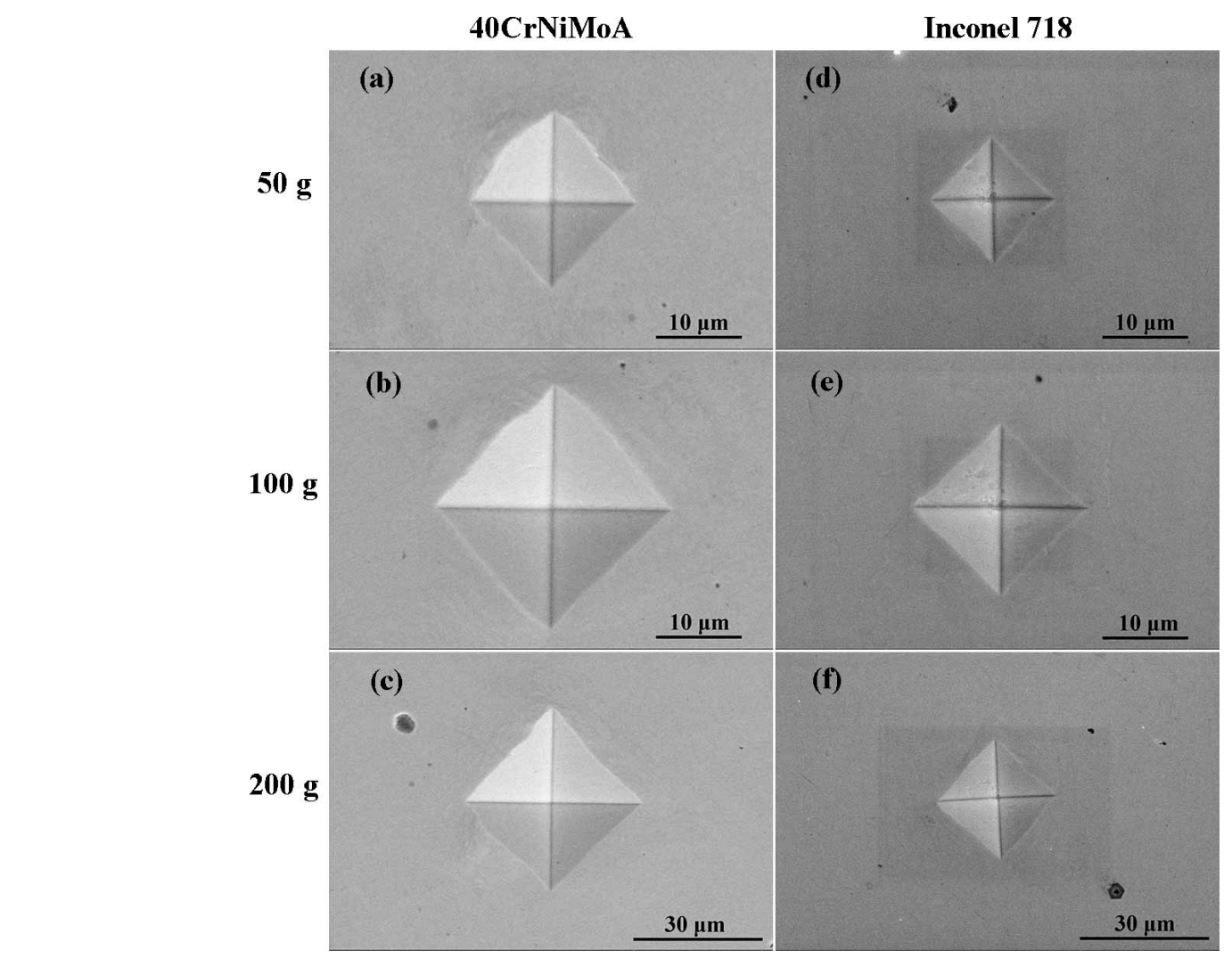
loadings. indentation size effect (ISE) [21, 22]. Inconel 718

Table 2 Vickers hardness of the two alloys under different

\begin{tabular}{cccc}
\hline \multirow{2}{*}{ Samples } & \multicolumn{3}{c}{ Load $(\mathrm{g})$} \\
\cline { 2 - 4 } & 50 & 100 & 200 \\
\hline 40CrNiMoA & $240.0 \pm 12.1 \mathrm{HV}$ & $233.4 \pm 16.5 \mathrm{HV}$ & $221.6 \pm 10.9 \mathrm{HV}$ \\
Inconel 718 & $483.8 \pm 9.8 \mathrm{HV}$ & $480.0 \pm 10.6 \mathrm{HV}$ & $471.8 \pm 8.3 \mathrm{HV}$ \\
\hline
\end{tabular}

high as that of $40 \mathrm{CrNiMoA}$ steel. As the applied loading increases, the indentation size becomes larger, and the microhardness values decrease gradually. This phenomenon is known as the

A qualitative comparison was further performed by checking the deformed cavity [23], as shown in Fig. 2. Even though the applied loading increases to $200 \mathrm{~g}$, such characteristic radial cracks cannot be observed, which reflects the high mechanical toughness values and considerable ductilities of both alloys. However, there is a clearly visible deformation at the edge of the 40CrNiMoA steel specimen after indentation due to plastic

Fig. 2 SEM micrographs of microhardness indentation of $(\mathrm{a}-\mathrm{c})$ 40CrNiMoA steel, and (d-f) Inconel 718 alloy under applied loadings of 50,100 , and $200 \mathrm{~g}$. 
anisotropy [24, 25], which can be seen in Fig. 2(c). On the contrary, Inconel 718 alloy does not demonstrate any mechanically induced damage, as shown in Figs. 2(d)-2(f). These microscopic observations prove that Inconel 718 alloy has a better mechanical capability than $40 \mathrm{CrNiMoA}$ steel.

Figure 3 shows the scratch features of $40 \mathrm{CrNiMoA}$ steel and Inconel 718 alloy after one-pass scratch testing, where the scratching depth values at different locations are automatically recorded by the $\mathrm{RST}^{3}$ scratch machine. The penetration depth and maximum residual depth of $40 \mathrm{CrNiMoA}$ steel are 23 and $18.5 \mu \mathrm{m}$, respectively, while Inconel 718 alloy has a penetration depth of $20.8 \mu \mathrm{m}$ and a maximum residual depth of $6.2 \mu \mathrm{m}$. As compared with the scratch track of Inconel 718 alloy, noticeable increases in scratch depth and width occur for the 40CrNiMoA steel with increasing applied loading. It was elucidated that severe delamination occurs for 40CrNiMoA steel, and Inconel 718 alloy demonstrates better resistance to scratching due to its superior strength [26].

Relevant failing mechanisms were further observed in Fig. 4. Under the continuous abrasion process with coupled vertical and lateral forces, 40CrNiMoA steel displays severe plastic deformation with the characteristics of the plowing action depicted in Figs. 4(a) and 4(c), where materials are squeezed out to both sides and visible bulges emerge along the scratch tracks. At a higher level of loading, the cracks are inclined to tear, and micro-cracking accompanied by a mild cutting mechanism takes place, yielding the highest scratch depth in Fig. 4(e). Similar failures, that is, the crack formed by tensile frictional stress behind the trailing edge of the stylus, can be found during the scratching evaluation of the coating material [27]. Inconel 718 alloy displays a mildly similar evolution as the scratching load increases, as shown in Fig. 4(b); however, a smoothening track without any cracks and craters appears. The failure mechanism is the plowing process, which is strongly associated with the good combination of ductility and strength of the Inconel 718 alloy [28]. In particular, the $\gamma$ phase of the Inconel 718 alloy matrix has a face-centered cubic structure with 12 independent slip systems, and it deforms plastically in a slipping form, as evidenced by the slip bands in Fig. 4(d). Based on these comprehensive mechanical evaluations, Inconel 718 alloy yields abrasion resistance and mechanical strength superior to those of $40 \mathrm{CrNiMoA}$ steel.

\subsection{High temperature friction and wear}

The averaged coefficients of friction (COF) of $40 \mathrm{CrNiMoA}$ steel and Inconel 718 alloy against the $\mathrm{Si}_{3} \mathrm{~N}_{4}$ counterpart are summarized in Fig. 5. Their frictional behaviors at different operational temperatures display some similarities for the two tribological pairs, temperature dependent. The COF of 40CrNiMoA steel and Inconel 718 alloy decreases with increasing operational temperatures. The COF at RT is 0.88 for $40 \mathrm{CrNiMoA}$ steel and 0.78 for Inconel 718 alloy, respectively. The results from tests at $800{ }^{\circ} \mathrm{C}$ illustrate that the COFs of $40 \mathrm{CrNiMoA}$ steel and Inconel 718 alloy reach the minimum values, which are as low as 0.52 and 0.32 , respectively. In total, the COF of $40 \mathrm{CrNiMoA}$ steel is relatively higher than that of Inconel 718 alloy for a wide range of testing temperatures. It can be

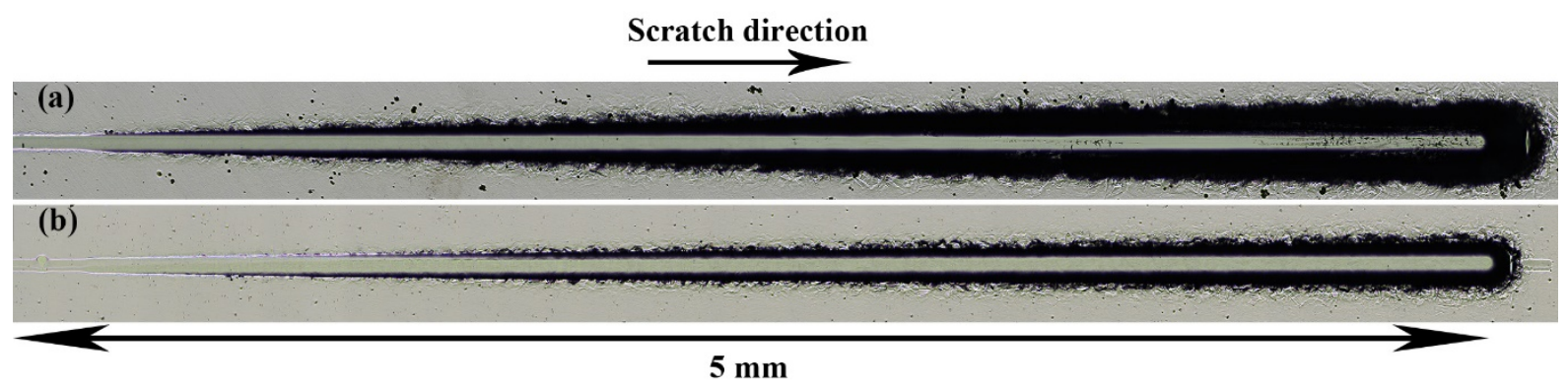

Fig. 3 Optical observation of scratch tracks of (a) 40CrNiMoA steel and (b) Inconel 718 alloy. 


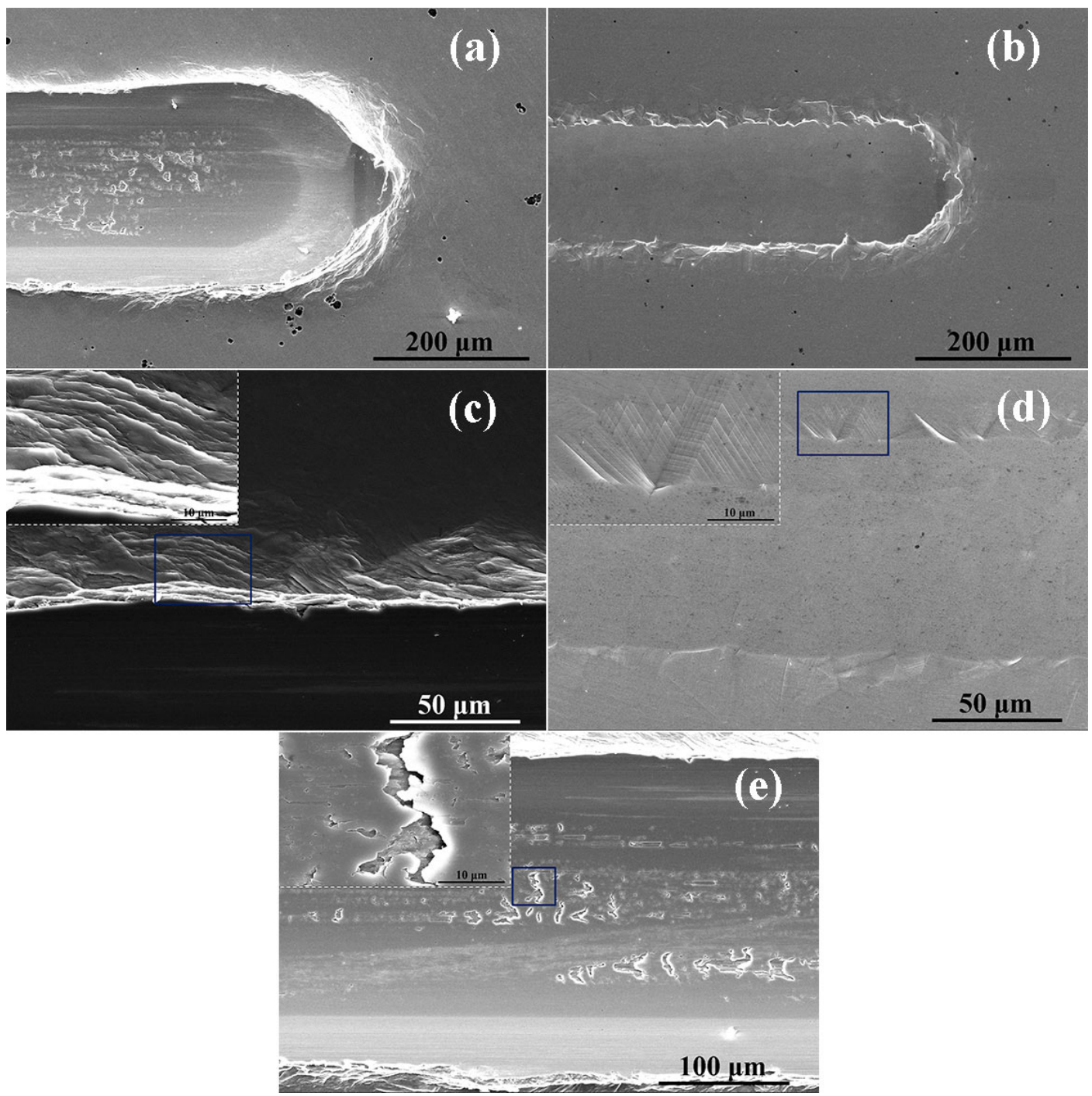

Fig. 4 SEM observation of the representative scratch tracks of (a, c, e) 40CrNiMoA steel and (b, d) Inconel 718 alloy.

seen that the testing temperature of $400{ }^{\circ} \mathrm{C}$ is a transition point during which the COFs for $40 \mathrm{CrNiMoA}$ steel and Inconel 718 alloy are close to each other. In the case of $40 \mathrm{CrNiMoA}$ steel, its COF drops drastically before $400{ }^{\circ} \mathrm{C}$ and the drop slows down at elevated temperatures. In contrast, the COF of Inconel 718 alloy decreases slowly before $400{ }^{\circ} \mathrm{C}$, and a quick decrease occurs after $400{ }^{\circ} \mathrm{C}$. These results imply temperature-mediated frictional features for two as-received alloyed materials, which are predominantly tailored by the developed tribolayer over the tribologically contacting surface [29].

During frictional tests at elevated temperatures, surface oxidation has a small influence on the

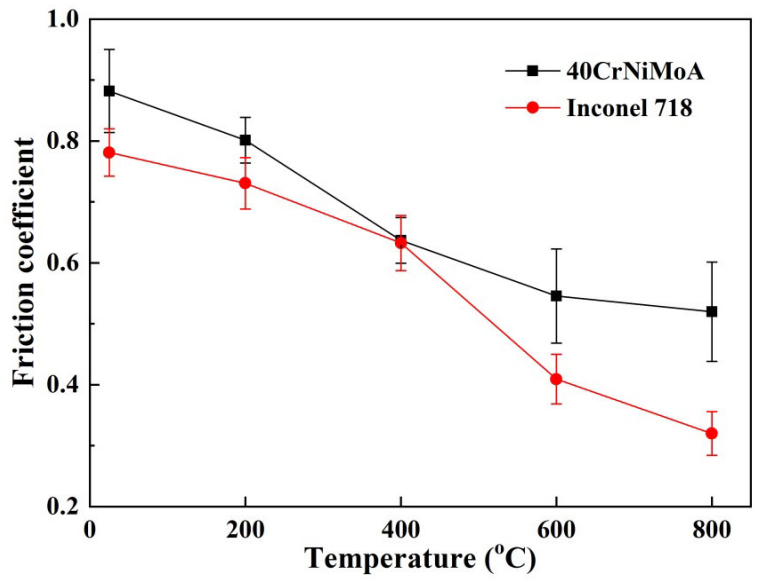

Fig. 5 Averaged coefficient of friction (COF) values of 40CrNiMoA steel and Inconel 718 alloy at different temperatures. 
resulting friction and wear behavior. However, the quantification of oxidation by weighing the specimens after the test is inaccurate owing to its negligible change in mass [30, 31]. Thus, the specific wear rates of $40 \mathrm{CrNiMoA}$ steel and Inconel 718 alloy are measured using a surface profiler, as shown in Fig. 6(a). The wear behavior of the two alloys sliding against ceramic $\mathrm{Si}_{3} \mathrm{~N}_{4}$ is temperature-dependent as well. The wear rate of $40 \mathrm{CrNiMoA}$ increases considerably with increasing temperature, which can likely be associated with the mechanical softening of $40 \mathrm{CrNiMoA}$ steel at elevated temperatures. The wear rate of Inconel 718 alloy displays a gradual decrease from RT to $600{ }^{\circ} \mathrm{C}$, although a further increase occurs at $800{ }^{\circ} \mathrm{C}$, which correlates with unexpected tribo-oxidation under the coupled temperature and stressed-shearing conditions. The specific wear rates of the $\mathrm{Si}_{3} \mathrm{~N}_{4}$ counterpart of $40 \mathrm{CrNiMoA}$ steel and Inconel 718 alloy are plotted as a function of temperature in Fig. 6(b). All counterpart $\mathrm{Si}_{3} \mathrm{~N}_{4}$ balls demonstrate similar wear behavior and reduction in wear when the temperature increases. In particular, minimum but equal wears appear for the $\mathrm{Si}_{3} \mathrm{~N}_{4}$ counterparts at $800{ }^{\circ} \mathrm{C}$. This can be explained to be associated with the decreasing yield strengths, reduced hardness values, and increasing ductilities of the alloys themselves under the gradually increasing temperature. Thus, the wear damage is not dominant, whereas plastic deformation occurs at $800{ }^{\circ} \mathrm{C}$ [32]. However, the wear rate of the $\mathrm{Si}_{3} \mathrm{~N}_{4}$

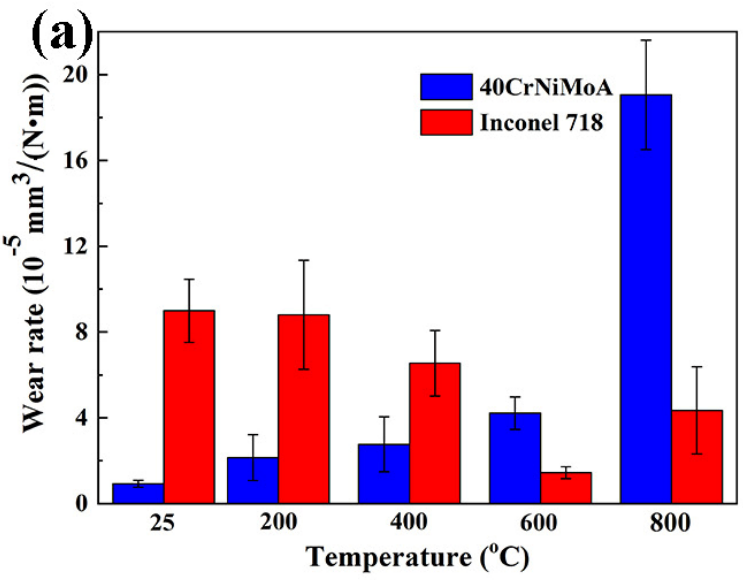

zcounterparts of the Inconel 718 alloy is less than that of $40 \mathrm{CrNiMoA}$ steel for a temperature range from RT to $600{ }^{\circ} \mathrm{C}$. As reported, the compacted oxidation layer often forms over silicon nitride during sliding, which is protective and able to resist wear [33]. It can be speculated that the tribolayer imparts a self-lubricating capability to silicon nitride. Further details are provided in the SEM/EDS analysis in Figs. 7 and 8 and Table 3.

\subsection{Temperature-mediated wear transition}

The microscopic characteristics of the worn surfaces of 40CrNiMoA steel and Inconel 718 alloy from 25 to $800{ }^{\circ} \mathrm{C}$ are shown in Fig. 7. The SEM micrographs show the removal of material fragments and some abrading action of oxidized wear debris by the evidence of some scoring marks and scattered debris on the 40CrNiMoA (Fig. 7(a)) and Inconel 718 alloy specimens (Fig. 7(f)), which yields higher friction between the rubbed contacts in Fig. 5. At $200{ }^{\circ} \mathrm{C}$, the predominant wear mechanism of $40 \mathrm{CrNiMoA}$ steel is abrasion, which is typical for a large quantity of wear debris and agglomeration of wear debris, as shown in Fig. 7(b); this is known as three-body abrasion. The Inconel 718 alloy demonstrates adhesion with distinguishable abrasion of oxidized wear debris and signs of debris compaction in Fig. $7(\mathrm{~g})$.

The wear characteristics at $400{ }^{\circ} \mathrm{C}$ for the two as-received specimens significantly differ from those at RT and $200{ }^{\circ} \mathrm{C}$, as shown in Figs. 7(c) and 7(h). Oxide wear debris and high abrasive severity

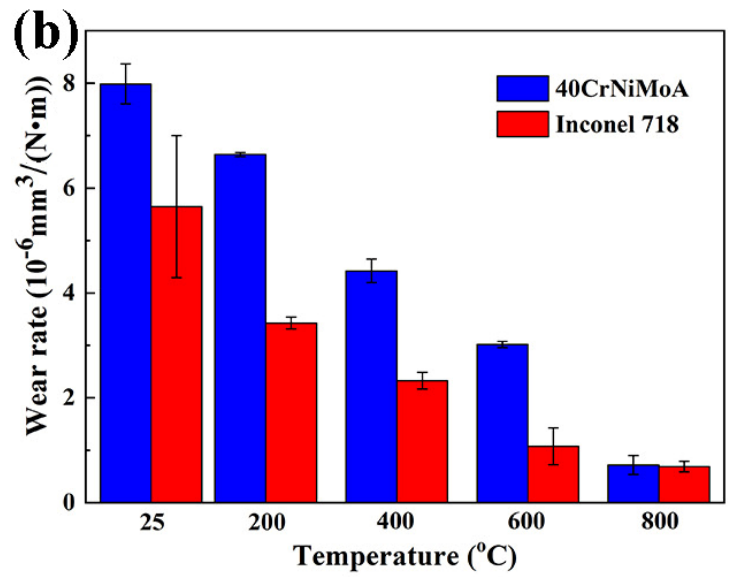

Fig. 6 Wear rate of (a) 40CrNiMoA steel and Inconel 718 alloy and (b) counterpart balls against the two materials at different temperatures. 


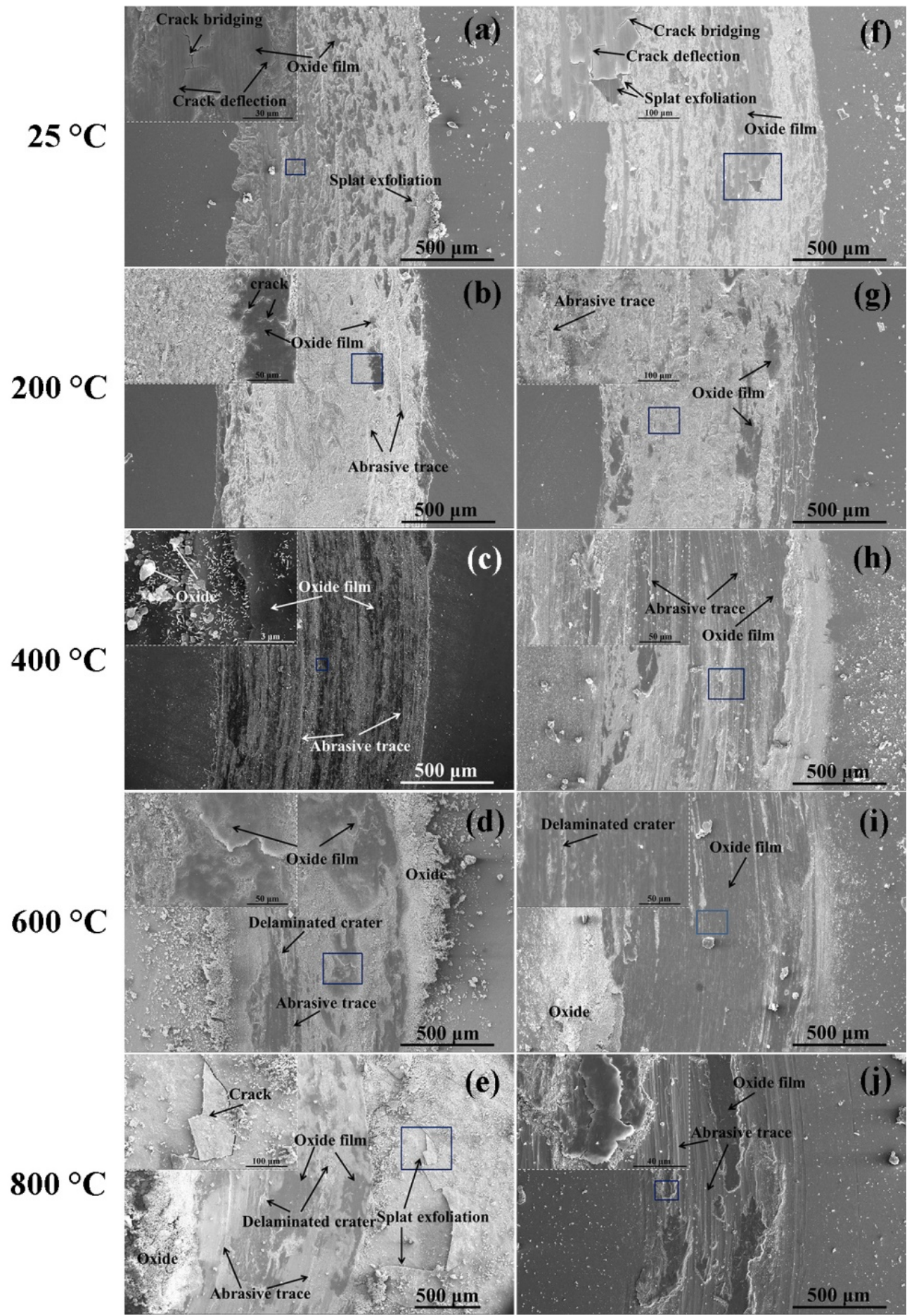

Fig. 7 SEM morphologies of worn scars and surfaces of (a-e) $40 \mathrm{CrNiMoA}$ steel, and ( $\mathrm{f}-\mathrm{j})$ Inconel 718 alloy from RT- $800{ }^{\circ} \mathrm{C}$.

can be found in the surrounding area of the wear track for 40CrNiMoA steel (Fig. 7(c)). A relatively smooth worn surface appears for the Inconel 718 alloy, where a compacted oxide film seemingly covers the surface (Fig. 7(h)). This can explain why the Inconel 718 alloy demonstrates a significant reduction in friction [34]. In contrast, large amounts of oxide debris accumulated on both sides of the wear surfaces of the two materials at $600{ }^{\circ} \mathrm{C}$ (Figs. 7(d) and 7(i)), which is a typical 
Table 3 Element contents (wt\%) on the wear scar of $\mathrm{Si}_{3} \mathrm{~N}_{4}$ counterparts against $40 \mathrm{CrNiMoA}$ steel and Inconel 718 alloy.

\begin{tabular}{|c|c|c|c|c|c|c|c|c|c|c|}
\hline \multicolumn{6}{|c|}{ 40CrNiMoA steel $\left({ }^{\circ} \mathrm{C}\right)$} & \multicolumn{5}{|c|}{ Inconel 718 alloy $\left({ }^{\circ} \mathrm{C}\right)$} \\
\hline & 25 & 200 & 400 & 600 & 800 & 25 & 200 & 400 & 600 & 800 \\
\hline $\mathrm{N}$ & - & - & - & - & - & - & - & - & - & - \\
\hline $\mathrm{O}$ & - & - & - & - & - & - & - & - & - & - \\
\hline $\mathrm{Al}$ & 2.31 & 2.26 & 2.27 & 0.08 & 1.89 & 2.45 & 2.20 & 1.27 & 1.73 & 1.15 \\
\hline $\mathrm{Si}$ & 71.78 & 69.55 & 64.79 & 53.73 & 69.65 & 70.72 & 70.72 & 81.25 & 63.38 & 75.55 \\
\hline $\mathrm{Nb}$ & 24.13 & 26.30 & 30.02 & 35.28 & 26.17 & 23.86 & 24.39 & 15.42 & 24.78 & 14.36 \\
\hline Mo & 0.10 & 0.21 & 0.83 & 8.85 & 0.09 & 0.26 & 0.28 & 0.42 & 0.45 & 0.30 \\
\hline $\mathrm{Ti}$ & 1.61 & 1.47 & 1.08 & 1.16 & 1.39 & 1.65 & 1.31 & 0.81 & 1.42 & 0.62 \\
\hline $\mathrm{Cr}$ & 0.01 & 0.02 & 0.11 & 0.14 & 0.03 & 0.13 & 0.13 & 0.11 & 1.80 & 0.93 \\
\hline $\mathrm{Fe}$ & 0.03 & 0.14 & 0.63 & 0.56 & 0.74 & 0.18 & 0.20 & 0.13 & 1.99 & 1.88 \\
\hline $\mathrm{Ni}$ & 0.03 & 0.07 & 0.27 & 0.20 & 0.03 & 0.74 & 0.77 & 0.57 & 4.33 & 5.20 \\
\hline
\end{tabular}

Note: - indicates that it is not detected.

feature of serious abrasion. Such delaminated craters can be found within the wear scars. The microscopic view further shows the different morphologies of the compacted oxide film on the wear surfaces of $40 \mathrm{CrNiMoA}$ steel and Inconel 718 alloy, where the oxide film is relatively loose and has poor adherence to 40CrNiMoA steel in Fig. 7(d) and is highly compacted for the Inconel 718 alloy in Fig. 7(i). The governing mechanisms at $800{ }^{\circ} \mathrm{C}$ for $40 \mathrm{CrNiMoA}$ steel are agglomeration of oxides and delaminated craters as well as serious exfoliation of the oxide layer in Fig. 7(e), which indicates that oxide is transferred to the opposite side [1]. The wear mechanism of the Inconel 718 alloy is mainly adhesive with severe scoring marks, as shown in Fig. $7(\mathrm{j})$. However, this oxide layer renders superior lubrication at elevated temperatures, thereby significantly reducing friction, as shown in Fig. 5. The transition in wear mechanism from 25 to $800{ }^{\circ} \mathrm{C}$ for $40 \mathrm{CrNiMoA}$ steel and Inconel 718 alloy is summarized in Table 4. As observed, a loose, compact layer is formed at $600{ }^{\circ} \mathrm{C}$ for $40 \mathrm{CrNiMoA}$ steel (Fig. $7(\mathrm{~d})$ ), whereas a dense oxide layer is formed at $200^{\circ} \mathrm{C}$ for the Inconel 718 alloy (Fig. $7(\mathrm{~g})$ ), which is consistent with the COFs of the two materials in Fig. 5.

Microscopic observation of the worn surfaces of $\mathrm{Si}_{3} \mathrm{~N}_{4}$ was also carried out using SEM, as shown in Fig. 8. As the temperature increases, the diameters of the wear scars on the paired $\mathrm{Si}_{3} \mathrm{~N}_{4}$ surface against $40 \mathrm{CrNiMoA}$ steel and Inconel 718 alloy become smaller, which is associated with the self-lubricating nature and thus the wear resistance of the progressively grown tribolayer on the paired $\mathrm{Si}_{3} \mathrm{~N}_{4}$ surface. At room and ambient temperatures, the worn surfaces are smooth, and abrasive grooves are visible, with the scattering of fine debris over silicon nitride against $40 \mathrm{CrNiMoA}$ steel shown in Figs. 8(a) and 8(b). When sliding against Inconel 718 alloy, debris and grooves occur along the sliding direction, which is clear evidence of abrasive wear. The worn surfaces are also relatively rough (Figs. $8(\mathrm{f})$ and $8(\mathrm{~g})$ ). Although this debris sometimes clumps together, there are many single particles scattered over the worn surface. At $400{ }^{\circ} \mathrm{C}$, many more particulate materials can be found at the trailing edge of the worn $\mathrm{Si}_{3} \mathrm{~N}_{4}$ surface against 40CrNiMoA steel (Fig. 8(c)) and against

Table 4 Wear mechanisms of 40CrNiMoA steel and Inconel 718 alloy at different temperatures.

\begin{tabular}{ccc}
\hline $25{ }^{\circ} \mathrm{C}$ & Oxidation and abrasion & Onconel 718 alloy \\
$200{ }^{\circ} \mathrm{C}$ & Oxidation and abrasion & $\begin{array}{c}\text { Oxidation and abrasion } \\
\text { Abrasion and debris } \\
\text { compaction }\end{array}$ \\
$400{ }^{\circ} \mathrm{C}$ & $\begin{array}{c}\text { Oxidation and serious } \\
\text { abrasion }\end{array}$ & Compacted oxide film \\
& $\begin{array}{c}\text { Serious Abrasion and } \\
600{ }^{\circ} \mathrm{C}\end{array}$ & $\begin{array}{c}\text { Foose compacted oxide } \\
\text { film }\end{array}$ \\
& Agglomerated oxides and & Adhesive and compacted \\
$800{ }^{\circ} \mathrm{C}$ & $\begin{array}{c}\text { compacted oxide film } \\
\text { oxide film }\end{array}$ \\
\hline
\end{tabular}




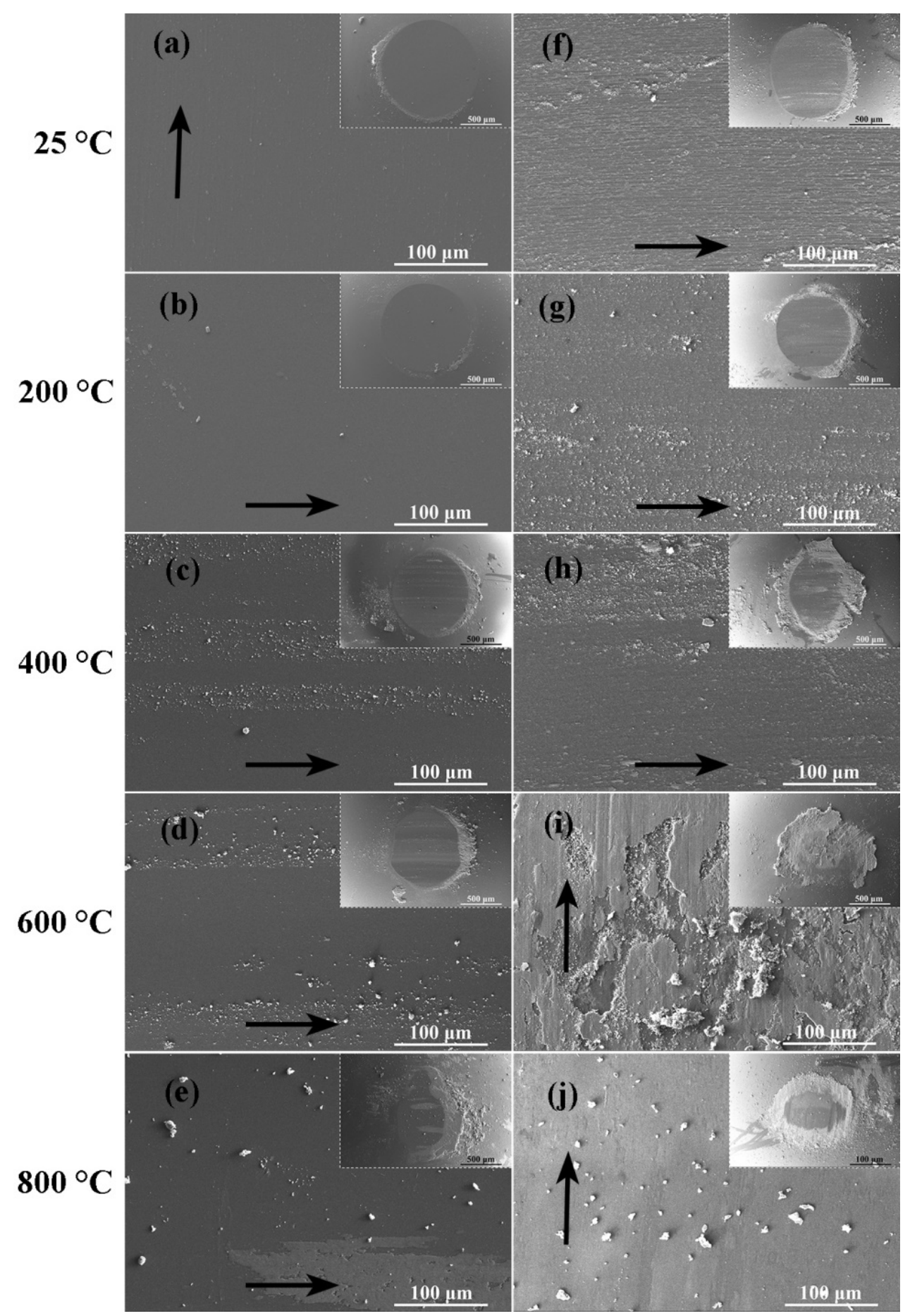

Fig. 8 SEM morphologies of worn scars over $\mathrm{Si}_{3} \mathrm{~N}_{4}$ counterparts: (a-e) 40CrNiMoA steel, and (f-j) Inconel 718 alloy from $\mathrm{RT}-800{ }^{\circ} \mathrm{C}$; arrows indicate sliding directions.

Inconel 718 alloy (Fig. 8(h)).

Nevertheless, the worn topographies at $600{ }^{\circ} \mathrm{C}$ are significantly different from those at relatively lower temperatures (Figs. 8(d) and 8(i)). There are accumulations of fine debris particles, some relatively adherent on the $\mathrm{Si}_{3} \mathrm{~N}_{4}$ sliding surface against 40CrNiMoA steel, as shown in Fig. 8(d); instead, severe adhesion and abrasive grooves are present under the Inconel 718 alloy-mated conditions shown in Fig. 8(i), where the structure 
undergoes a process of severe plastic deformation. At $800{ }^{\circ} \mathrm{C}$, when wear is relatively low, smooth tribolayers are constructed over the worn silicon nitride against 40CrNiMoA steel (Fig. 8(e)) and Inconel 718 alloy (Fig. 8(j)). This thin layer separates the rubbing surfaces and reduces friction.

\subsection{SEM/EDS identification of worn surfaces}

EDS line analyses across the worn surfaces of 40CrNiMoA steel in Figs. 9(a)-9(e) show the visible silicon within the worn surface at room/ ambient temperatures, due to material transfer. EDS line analyses across the worn surfaces of Inconel 718 alloy (Figs. 9(f)-9(j)) demonstrates similar characteristics; all worn surfaces include a significant amount of oxygen, which definitely affirms intensive oxidation during sliding. A careful comparison of the oxygen intensity, as shown in Fig. 9, shows that the oxygen concentration within the central contacting area is much higher than those at both edges of the wear track with the exception of Figs. 9(d), 9(e), and 9(j), which arises from the accumulation of abrasive debris during the thermomechanical process. Note that $40 \mathrm{CrNiMoA}$ steel is more severely oxidized than the Inconel 718 alloy. Although it is relatively difficult to determine the accurate extent of oxidation, oxidation intensifies with temperature within and outside the worn surface [35], and 40CrNiMoA steel is more severely oxidized than the Inconel 718 alloy because of the lack of $\mathrm{Cr}$ in the former [36].

The elemental distributions inside and outside the wear tracks of $40 \mathrm{CrNiMoA}$ steel and Inconel 718 alloy are shown in Figs. 10 and 11, respectively. In comparison, the abrasion of $\mathrm{Fe}_{2} \mathrm{O}_{3}$ decreases as temperature increases from RT to $800{ }^{\circ} \mathrm{C}$, whereas it behaves as a lubricant at elevated temperatures. Another noticeable feature is increasing molybdenum concentration within the worn area in response to increasing temperature, which indicates that molybdenum oxide significantly contributes to the frictional decrement at elevated

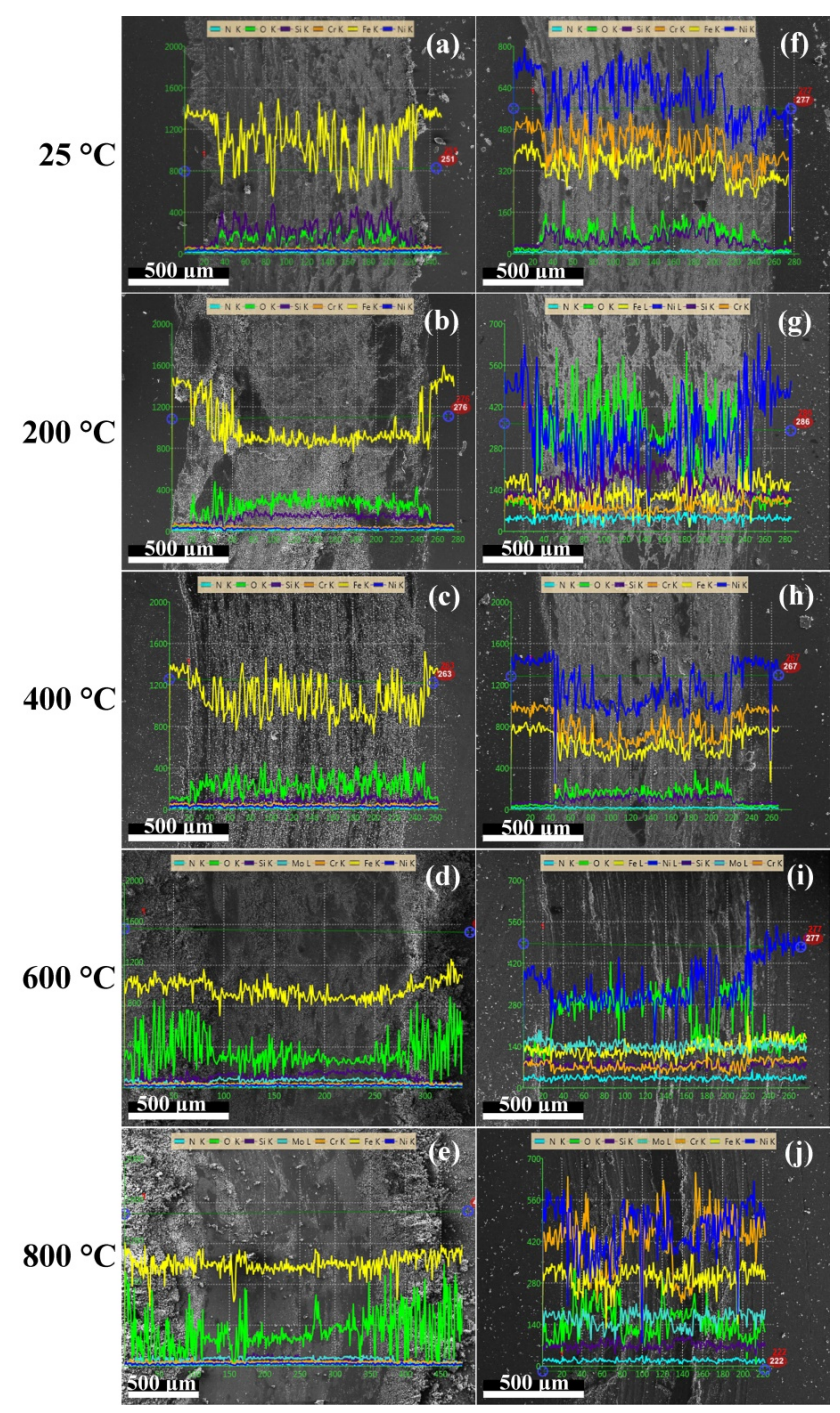

Fig. 9 EDS line analyses of element content on the wear surface of (a-e) 40CrNiMoA steel and (f-j) Inconel 718 alloy from RT $-800{ }^{\circ} \mathrm{C}$.

temperatures.

A similar distributional characteristic of Fe can be observed inside and outside the wear tracks of Inconel 718 alloy (Fig. 11) compared to that of $40 \mathrm{CrNiMoA}$ steel. In particular, the increasing accumulation of $\mathrm{Mn}, \mathrm{N}$, and $\mathrm{Nb}$ within the wearing region is seemingly homogeneous, especially at $800{ }^{\circ} \mathrm{C}$. In contrast, the distributions of $\mathrm{Cr}$ and $\mathrm{Ni}$ are more dominant in the central wearing area, which imply that the temperature-dependent tribological behavior of the Inconel 718 alloy is associated with the formation of a lubricating surface primarily 


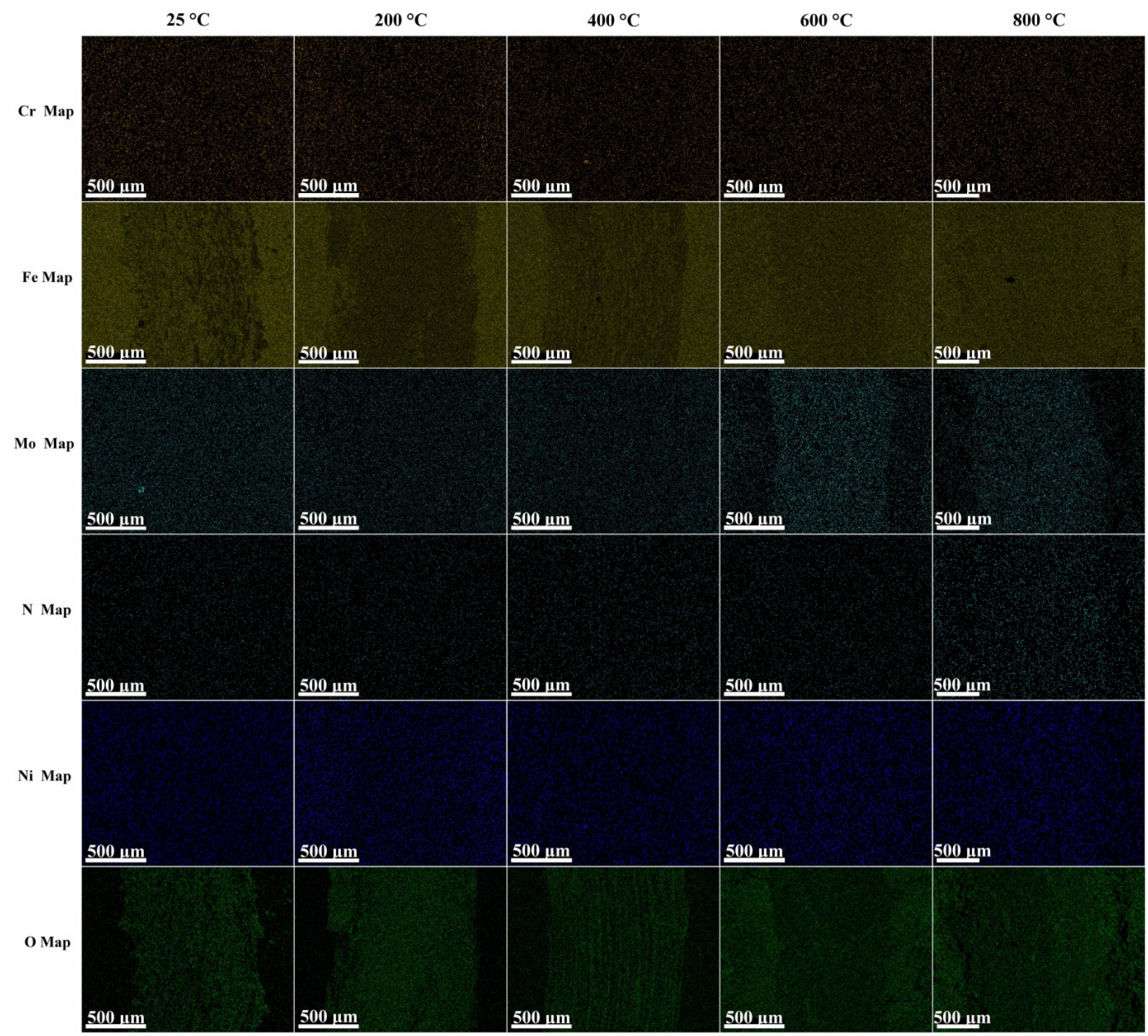

Fig. 10 Elemental distribution maps of $40 \mathrm{CrNiMoA}$ steel from RT-800 ${ }^{\circ} \mathrm{C}$.

composed of $\mathrm{Fe}, \mathrm{Cr}$, and $\mathrm{Ni}$.

An EDS mapping analyses are conducted on the counterparts sliding against $40 \mathrm{CrNiMoA}$ steel and Inconel 718 alloy (Fig. 12). For $\mathrm{Si}_{3} \mathrm{~N}_{4}$ paired with 40CrNiMoA steel, EDS mapping proves that a large amount of $\mathrm{Fe}$ is transferred onto the worn $\mathrm{Si}_{3} \mathrm{~N}_{4}$ surface with intensive oxidation (Fig. 12(b)). When sliding against Inconel 718 alloy, the $\mathrm{Fe}, \mathrm{Cr}$, $\mathrm{Ni}, \mathrm{Mo}$, and $\mathrm{O}$ are distinguishable on the worn $\mathrm{Si}_{3} \mathrm{~N}_{4}$ surface, as shown in Figs. 12(f)-12(o). EDS analysis reveals a fraction of material transfer and thereby a tribochemical layer with lubricating ability on the $\mathrm{Si}_{3} \mathrm{~N}_{4}$ surface.

It is clear that material transfer occurs, and a compact oxide layer covers the worn $\mathrm{Si}_{3} \mathrm{~N}_{4}$ surface when it matches the Inconel 718 alloy at $800{ }^{\circ} \mathrm{C}$. This layer is made up of $\mathrm{Fe}, \mathrm{Cr}, \mathrm{Ni}, \mathrm{Mo}$, and $\mathrm{O}$. However, once the tribo-oxide layer is too thick, it separates easily and wears away [37], causing a sudden increase in wear loss at $800{ }^{\circ} \mathrm{C}$, as shown in Fig. 6(a).

It has been acknowledged that material transfer facilitates the restoration of the contacting surface by constructing a lubricant layer primarily consisting multiple oxides, thus reducing friction and improving the wear resistance. As shown in Table 3, when sliding against Inconel 718 alloy, the dominant elements on the wear scar of $\mathrm{Si}_{3} \mathrm{~N}_{4}$ are 


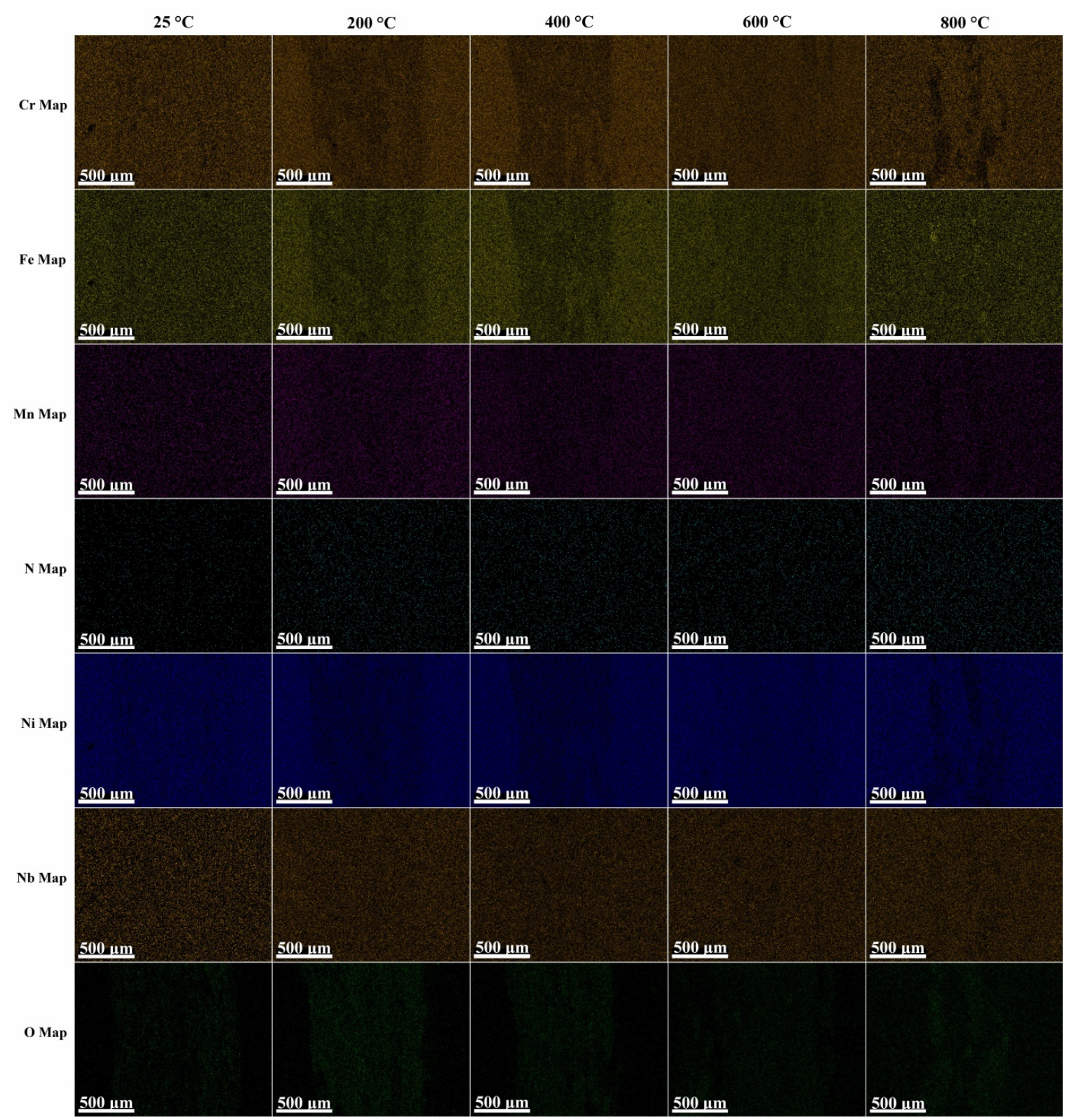

Fig. 11 Elemental distribution maps of Inconel 718 alloy from RT-800 ${ }^{\circ} \mathrm{C}$.

Mo, $\mathrm{Ni}, \mathrm{Cr}$, and $\mathrm{Fe}$, while the $\mathrm{Si}_{3} \mathrm{~N}_{4}$ counterparts sliding against $40 \mathrm{CrNiMoA}$ steel show the transfer of $\mathrm{Mo}, \mathrm{Ni}$, and $\mathrm{Fe}$. The different wear rates of $\mathrm{Si}_{3} \mathrm{~N}_{4}$ are intrinsically associated with the composition of the tribolayer due to material transfer. Thus, the difference in the constituents of the tribolayer leads to the resulting wear variety of $\mathrm{Si}_{3} \mathrm{~N}_{4}$ counterparts against Inconel 718 alloy and 40CrNiMoA steel, as shown in Fig. 6(b). However, it was barely detectable for $\mathrm{N}$ and $\mathrm{O}$ elements on the wear scars of $\mathrm{S}_{3} \mathrm{~N}_{4}$ counterparts against
40CrNiMoA steel and Inconel 718 alloy, respectively. It is true that the analysis of the $\mathrm{N}$ by EDS is generally regarded as qualitative and for informative purposes only because of its low fluorescence yield, absorption, and peak overlaps with higher elements in the $\mathrm{L}, \mathrm{M}$, and $\mathrm{N}$ lines [38]. In the case of $\mathrm{O}$, the amount of $\mathrm{O}$ is definitely present within the transfer layer, but it is much lower than the resolution (0.1\%) of the EDS equipment used in this study [39]. Thus, the contents of $\mathrm{N}$ and $\mathrm{O}$ are not provided in Table 3. 


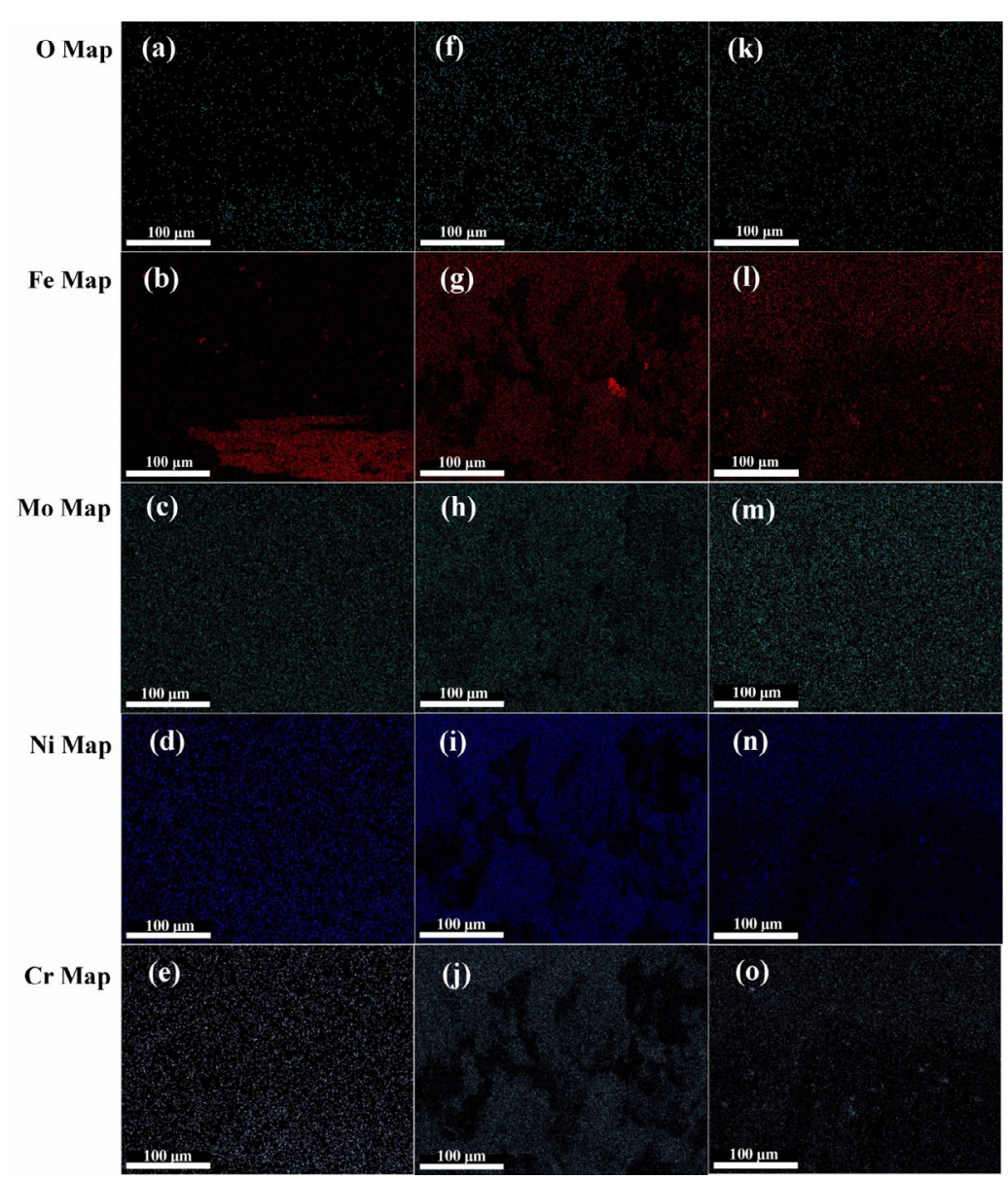

Fig. 12 Elemental distribution maps on the worn $\mathrm{Si}_{3} \mathrm{~N}_{4}$ surface against (a-e) $40 \mathrm{CrNiMoA}$ steel at $800{ }^{\circ} \mathrm{C}$, (f-j) Inconel 718 alloy at $600{ }^{\circ} \mathrm{C}$, and $(\mathrm{k}-\mathrm{o})$ Inconel 718 alloy at $800{ }^{\circ} \mathrm{C}$.

\subsection{Raman analysis of the inside and outside the wear track}

The phase composition inside and outside the worn surface of 40CrNiMoA steel and Inconel 718 alloy are analyzed by micro-Raman spectroscopy (Fig. 13). The observations confirm that the oxide phase occurs within the worn surface and is corroborated by comparison with the oxides on the outer worn surface, which stem from static oxidation. For the $40 \mathrm{CrNiMoA}$ steel, $\mathrm{MoO}_{3}, \mathrm{Fe}_{2} \mathrm{O}_{3}$, and $\mathrm{MnO}_{2}$ are present outside the worn region in Fig. 13(a), which can be identified by the representative peaks at 290,411, and $1,319 \mathrm{~cm}^{-1}$, respectively [40-42]. This is associated with the oxidation kinetics of individual elements within $40 \mathrm{CrNiMoA}$ steel [43]. However, these peaks are still observable for the inner worn area (Fig. 13(b)) and are more intense and narrower with increasing temperature, which is due to the increasing crystallinity and grain coarsening of the oxide formed in the wear track [44]. Thus, friction-induced changes in the composition of a surface layer occur. At relatively low temperatures, hard $\mathrm{Fe}_{2} \mathrm{O}_{3}$ debris and the oxygen-absorber $\mathrm{Mn}$ readily create a preventive layer on the sliding surface, a typical mechanism of oxidative wear accompanied with medium abrasion (Figs. 7(a, b) and $8(a, b))$, which reduces wear, as demonstrated in Fig. 6(a). When the sliding test exceeds $400{ }^{\circ} \mathrm{C}$, significantly more $\mathrm{MoO}_{3}$ gradually appears on the worn surface and restores the amount of contact between the rubbed pairs, thereby lowering friction and inhibiting wear. As reported, $\mathrm{MoO}_{3}$ is a volatile compound that is constantly ground into the worn surface $[45,46]$. It prefers to interact with surrounding media and forms molybdate; nevertheless, this compound is scarcely detected 

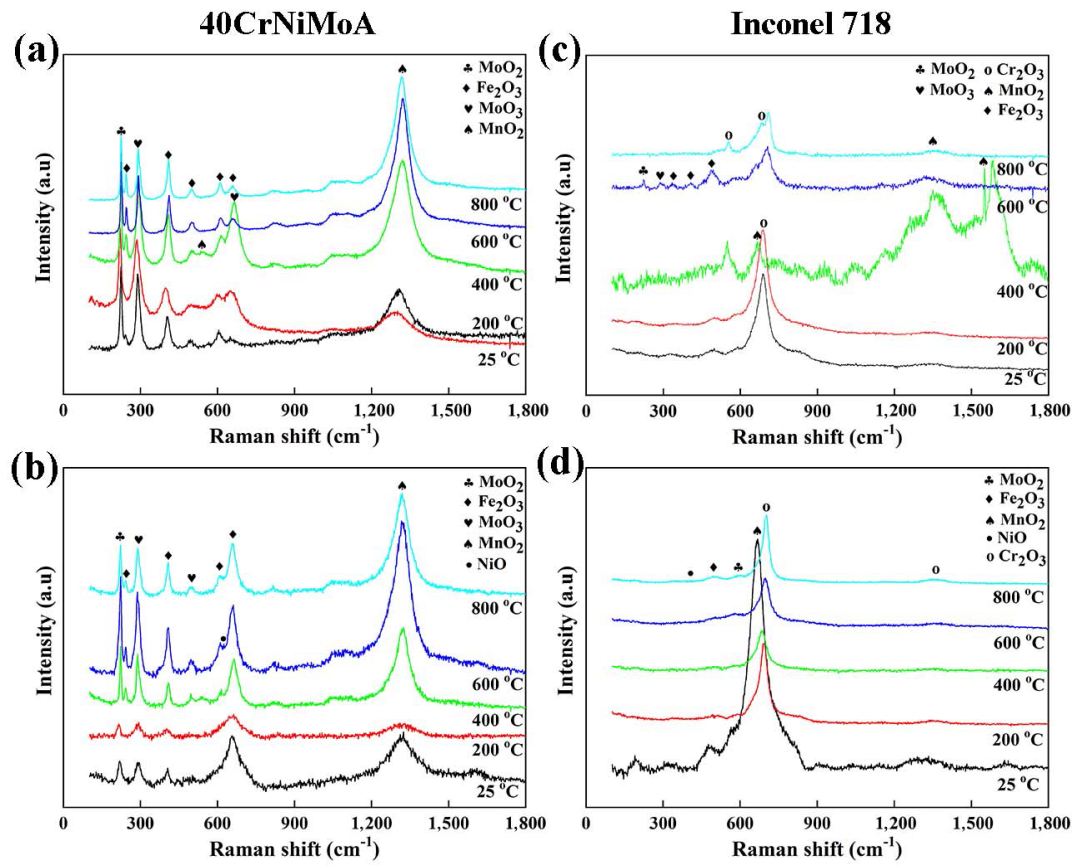

Fig. 13 Raman spectra of $(a, c)$ unworn surface and $(b, d)$ worn area of the two materials from RT $-800{ }^{\circ} \mathrm{C}$.

in this study.

Inconel 718 alloy includes various alloying constituents that influence oxidation during the static heat treatment and sliding. As shown in Fig. 13(c), at room/ambient temperatures, a layer mainly comprising $\mathrm{Cr}_{2} \mathrm{O}_{3}$ is formed on the Inconel 718 alloy. Some duplex oxides such as spinel $\mathrm{NiFe}_{2} \mathrm{O}_{4}$ simultaneously exist near the surface [47, 48]. As the temperature is above $400{ }^{\circ} \mathrm{C}$, in addition to $\mathrm{Cr}_{2} \mathrm{O}_{3}$, significantly more $\mathrm{MnO}_{2}$ emerges, where the Raman peaks at 685 and $663 \mathrm{~cm}^{-1}$ are assigned to $\mathrm{Cr}_{2} \mathrm{O}_{3}$ and $\mathrm{MnO}_{2}$, respectively $[49,50]$. However, if the temperature is increased to $800{ }^{\circ} \mathrm{C}$, the surface will not only contain a significant amount of $\mathrm{Cr}_{2} \mathrm{O}_{3}$, but it will also contain a minimal amount of oxides of other alloying constituents, which is attributed to the superior protection of the $\mathrm{Cr}_{2} \mathrm{O}_{3}$ layer on Inconel 718 alloy, which effectively limits the inward attack of oxygen and is simultaneously supported by the lower outward diffusion rate of Cr ions [51-53].

Nevertheless, there is a significant variation in the composition of the worn surface shown in Fig. 13(d). At RT, ferric oxide located at $498 \mathrm{~cm}^{-1}$ [54] and manganese oxide phase are mainly responsible for the low friction, where the $\mathrm{MnO}_{2}$ emerging facilitates surface smoothening [55]. As a comparison, completely different oxides within the worn surface are formed at elevated temperatures. For example, at $800{ }^{\circ} \mathrm{C}$ the dominant formation of the $\mathrm{Cr}_{2} \mathrm{O}_{3}$ layer is the main reason for the lower friction and wear observed in Figs. 5 and 6(a). The varying degree of oxidation of Inconel 718 alloy, along with the forms of the resulting oxides on the solid surface, are strongly influenced by temperature as well as the surface chemistry during friction, resulting in a significant change in friction and wear.

\subsection{Justification of tribo-oxidation and static oxidation}

The oxide films inside and outside the worn surface of the two as-received materials are depicted as observed from the cross-section view in Fig. 14. The common feature of increasing thickness with temperature elevation is clearly distinguishable: at room/ambient temperatures, abrasive oxide grains are ground onto the worn area, while static oxidation is barely identifiable for the two as-received materials because the 


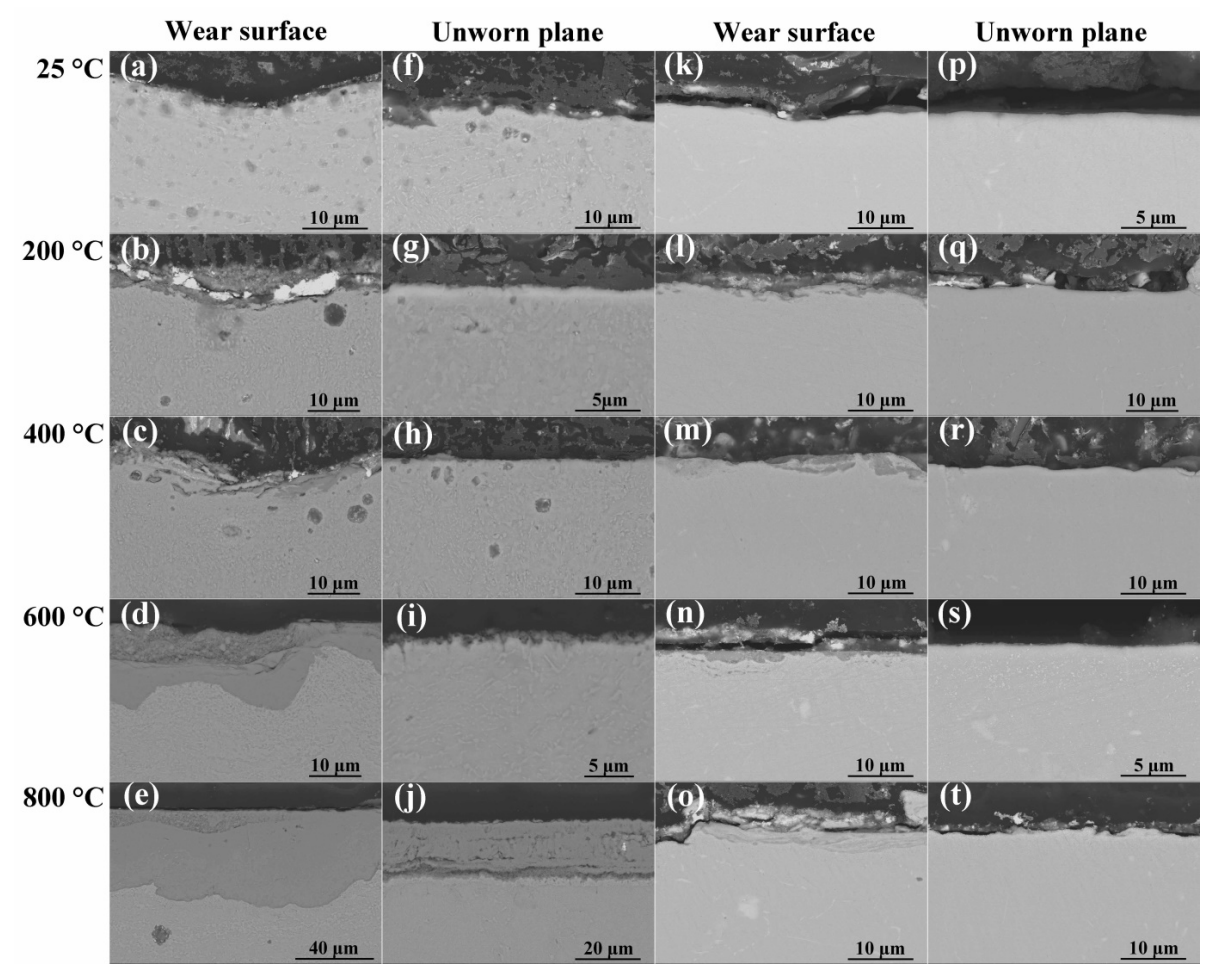

Fig. 14 SEM cross-section micrographs of oxide layers of $(a-j) 40$ CrNiMoA steel and (k-t) Inconel 718 alloy at different temperatures.

temperature does not exceed $400{ }^{\circ} \mathrm{C}$. Generally, approximately 500-nm-thick-fine oxide film deposits on the rubbed metallic surface at lower temperatures [56] and behaves as either positive abrasion or undesired three-body action [57]. It can be concluded that the stressed-shearing action during friction augments the growing oxides within the worn area [58]. In particular, as the temperature reaches $600{ }^{\circ} \mathrm{C}$, a static oxide layer on $40 \mathrm{CrNiMoA}$ steel is observable, approximately 1.3 $\mu \mathrm{m}$ thick in Fig. 14(i), and the average thickness of the oxide layer up to $12.1 \mu \mathrm{m}$ can be found within the wear track in Fig. $14(\mathrm{~d})$. At $800{ }^{\circ} \mathrm{C}$ the oxide layer within the worn surface of $40 \mathrm{CrNiMoA}$ steel is very thick, approximately $41.3 \mu \mathrm{m}$ in Fig. 14(e), while the static oxidative products have a thickness of approximately $18.4 \mu \mathrm{m}$ in Fig. 14(j).

The Inconel 718 alloy demonstrates a discontinuous oxide film with a maximum average thickness of 1 $\mu \mathrm{m}$ within the wear track, which further reflects dominant abrasive grooves present at room/ambient temperatures. As the temperature increases to $800{ }^{\circ} \mathrm{C}$, an oxide layer about $2.3 \mu \mathrm{m}$ thick can be clearly observed within the worn area in Fig. 14(o).
Compared with the static oxidation of $40 \mathrm{CrNiMoA}$ steel, only mild oxidation occurs inside and outside the worn surface, which is reported to be related to the presence of dense $\mathrm{Cr}_{2} \mathrm{O}_{3}$ [59], which prevents Inconel 718 alloy from wear and oxidative corrosion. This can be further evidenced by the absence of the oxide film at RT in Fig. 14(p), and the presence of a thin oxide film less than $1 \mu \mathrm{m}$ during static oxidation at $800{ }^{\circ} \mathrm{C}$ as shown in Fig. 14(t). The images reveal that the frictional process accelerates the growth of the oxide film as compared to static oxidation.

Raman spectra collected from inside and outside the worn surface illustrate the variation in the chemical composition of the developing oxide surface in response to temperature. The difference in the oxide layer inside and outside the wear track is further clarified in Fig. 13. As reported by Wahl et al. [60], metal oxides become soft when the temperature falls within $0.4-0.7$ of the absolute melting temperature. It is noted that softened $\mathrm{MnO}_{2}$ preferentially adheres to the wear track at higher contact temperatures, where Mn has much higher mobility and needs more oxygen for 
stabilization than those of other alloying elements such as Fe [61]. Thus, we observed intense peaks corresponding to $\mathrm{MnO}_{2}$ on the worn surface for the two alloyed materials.

\subsection{Discussion}

According to the theories of oxidational wear [62, 63], the tribological characteristics depend on the chemical and mechanical properties of the resulting oxides, their thicknesses and adherences over the sliding surface, wearing variations, and surface roughness values of the contacting surfaces. In general, the friction-induced rise in temperature accelerates the oxidation of the sliding surface. If the oxide film has low shearing strength, it enables effective lubrication between the rubbing surfaces, thereby reducing friction and wear. Normally, a film with sufficient thickness and good adherence can separate the solid surfaces from contact and thus inhibit wear [64]. Instead, the comparatively harder oxide particles behave as an abrasive medium that causes an unwanted wear increase. Coupled stressed-shearing and temperature during friction critically affect the heat generation/dissipation, interfacial temperature, and kinetics of oxide film formation and its composition [65]. The exact nature of the variation in wear rate and COF with temperature is largely dependent upon the underlying wear mechanisms, during which the restoration of oxide debris over the sliding surface is critical. The morphological identification in Section 3.3 indicates the formation of a tribo-oxide surface with multiple steps, for example, the fragmentation of wear debris and its subsequent oxidation, followed by agglomeration and compaction. If the temperature is sufficiently high, the tribo-oxide debris can be sintered, forming a shiny glaze layer. This glaze layer has been reported to be effective to reduce friction and prevent wear, particularly in nickel-based alloy systems [66-68]. In this study, similar characteristics were also found. A plot of temperature, $\mathrm{COF}$, and wear rate is shown in Fig. 15.

The COF decreases with the increase in operational temperature, as shown in Fig. 15. A similar tendency in the wear rate and friction can be observed due to the temperature, which is

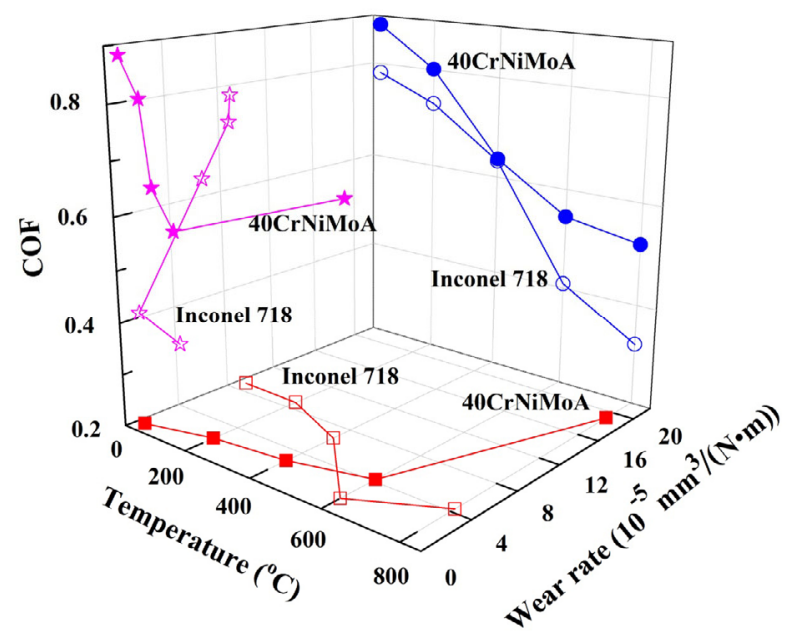

Fig. 15 Changes in temperature, wear rate, and COF.

largely dependent on the formation of the tribo-oxide film, as discussed in Section 3.3. SEM/EDS analysis of worn surfaces further supported these observations. With increasing temperatures, the interaction of the resulting oxides and the softening process of the materials themselves substantially determines the tribological performance; thus, the material demonstrates different tribological responses in Figs. 5 and 6. The tribo-induced oxide layer is mostly reported to deliver lubrication and contributes to a lower $\mathrm{COF}$ and wear rate [33]. However, although COF decreases, the metallic matrix inherently softens at elevated temperatures, resulting in an increase in wear. In this study, no mechanical value at elevated temperature is present, but it is true that the sliding surface softens due to temperature, which alters the adhesion between the tribo-oxide film and the substrate. This increases the fracturing possibility of the tribo-oxide film. As shown in Figs. 7(e) and $7(\mathrm{f})$, delamination cracking is closely associated with thermal shock stresses induced by the mismatch in the thermal expansion of carbides and oxides [69]. Normally, the friction between two unlubricated surfaces arises owing to adhesion and plowing, where the plowing component plays a critical role in abrasive wear. If fine abrasive particles are present, the adhesion component can play an important role in influencing COF $[70,71]$. At lower temperatures, the abrasive wear mechanisms are dominated by the plowing processes. At higher 
temperatures, the wear process is dominated by the oxidative wear, during which a relatively thick oxide film reduces the true area of contact. The corresponding decrease in COF at elevated temperatures is shown in Fig. 5.

Under the surrounding conditions, a very thin oxide layer is often present on metallic surfaces. For instance, even after polishing, specimens often have an oxide thickness of several nanometers. However, a thick oxide layer grows up to several microns during friction, as shown in Fig. 14, compared with static oxidation. This demonstrates the significance of the stressed-shearing action, which accelerates the oxidation during friction. In particular, a higher contact temperature promotes oxidative kinetics during sliding. However, if the oxide layer is too thick, it will break up and form particles [37]. Consequently, the wear rate depends significantly on the oxidation. The inconsistency in the correlation between the friction and wear of the two alloyed materials can be attributed to the change in the contribution of surface chemistry and mechanical properties with varying temperature [69, 70]. The results of the present work are fairly consistent with earlier observations on coated and uncoated specimens [72, 73].

\section{Conclusions}

This study focused on the effect of temperature on the friction and wear characteristics of 40CrNiMoA steel and Inconel 718 alloy when sliding against a ceramic $\mathrm{Si}_{3} \mathrm{~N}_{4}$ counterpart in order to clarify the role of tribo-oxidation and thermal-induced oxidation in tribological capabilities. The COF and abrasive wear rates of the two as-received materials decrease with increasing temperature. When paired with ceramic silicon nitride, the superior mechanical strength of Inconel 718 alloy to that of $40 \mathrm{CrNiMoA}$ steel is considered to be mainly responsible for the lower wear rate of the Inconel 718 alloy/Si $\mathrm{N}_{4}$ pair at lower temperatures. At elevated temperatures, reduced wear and COF for the Inconel 718 alloy $/ \mathrm{Si}_{3} \mathrm{~N}_{4}$ pair results from the formation of a lubricating oxide film consisting of $\mathrm{Cr}_{2} \mathrm{O}_{3}$, whereas the tribochemical layer with a simultaneous softening feature of the material base leads to lower friction but higher wear. Stressed-shearing action during friction accelerates oxide growth within the worn area. Thus, the tribo-induced oxidation plays a dominant role in the tribological performance across a wide range of temperatures. However, thermally induced oxidation and softening of the materials themselves become important with increasing temperature, and thereby contribute to the transition in tribology. The variations in wear and COF are intrinsically associated with varying composition on the solid surface, which can be attributed to the competition between tribo-chemical oxidation, thermally induced oxidation, and softening.

\section{Author contributions}

S Wan conceived, designed the study, reviewed the edited manuscript. L Bai performed the experiments and drafted the manuscript. G Yi and $Y$ Shan provided the raw materials and technical support, S T Pham and A K Tieu reviewed and edited the manuscript, $\mathrm{Y} \mathrm{Li}$ and $\mathrm{R} \mathrm{D}$ Wang provided two alloys in this study. All authors read and approved the manuscript.

\section{Acknowledgements}

The research received great support from the National Natural Science Foundation of China (Nos. 51575505 and 51675508). The work is also funded by Australian Research Council (ARC) Discovery Project (DP) (No. 150103718).

Open Access This article is licensed under a Creative Commons Attribution 4.0 International License, which permits use, sharing, adaptation, distribution and reproduction in any medium or format, as long as you give appropriate credit to the original author(s) and the source, provide a link to the Creative Commons licence, and indicate if changes were made.

The images or other third party material in this article are included in the article's Creative 
Commons licence, unless indicated otherwise in a credit line to the material. If material is not included in the article's Creative Commons licence and your intended use is not permitted by statutory regulation or exceeds the permitted use, you will need to obtain permission directly from the copyright holder.

To view a copy of this licence, visit http:// creativecommons.org/licenses/by/4.0/.

\section{References}

[1] Barrau O, Boher C, Vergne C, Rezai-Aria F, Gras R. Investigations of friction and wear mechanisms of hot forging tool steels. In 6th International Tooling Conference, Karlstad, Sweden, 2002: 81-94.

[2] So H, Chen C T, Chen Y A. Wear behaviours of laser-clad stellite alloy 6. Wear 192(1-2): 78-84 (1996)

[3] Wang X J, Yao X M, Zhang H, Liu X J, Huang Z R. Microstructure and tribological performance of mesocarbon microbead-silicon carbide composites. Materials 12(19): 3127 (2019)

[4] Torgerson T B, Mantri S A, Banerjee R, Scharf T W. Room and elevated temperature sliding wear behavior and mechanisms of additively manufactured novel precipitation strengthened metallic composites. Wear 426-427: 942-951 (2019)

[5] Du L M, Lan L W, Zhu S, Yang H J, Shi X H, Liaw P K, Qiao J W. Effects of temperature on the tribological behavior of $\mathrm{Al}_{0.25} \mathrm{CoCrFeNi}$ high-entropy alloy. J Mater Sci Technol 35(5): 917-925 (2019)

[6] Wan S H, Tieu A K, Xia Y N, Zhu H T, Tran B H, Cui S G. An overview of inorganic polymer as potential lubricant additive for high temperature tribology. Tribol Int 102: 620-635 (2016)

[7] Dhanasekaran S, Gnanamoorthy R. Abrasive wear behavior of sintered steels prepared with $\mathrm{MoS}_{2}$ addition. Wear 262(5-6): 617-623 (2007)

[8] Hernandez S, Hardell J, Winkelmann H, Ripoll M R, Prakash B. Influence of temperature on abrasive wear of boron steel and hot forming tool steels. Wear 338-339: 27-35 (2015)

[9] Pearson S R, Shipway P H, Abere J O, Hewitt R A A. The effect of temperature on wear and friction of a high strength steel in fretting. Wear 303(1-2): 622-631 (2013)

[10] Österle W, Urban I. Friction layers and friction films on
PMC brake pads. Wear 257(1-2): 215-226 (2004)

[11] Reddy K M, Mukhopadhyay A, Basu B. Microstructuremechanical-tribological property correlation of multistage spark plasma sintered tetragonal $\mathrm{ZrO}_{2}$. J Eur Ceram Soc 30(16): 3363-3375 (2010)

[12] Thirugnanasambantham K G, Raju R, Sankaramoorthy T, Velmurugan P, Kannagi A, Reddy M C K, Chary V S K, Mustafa M A, Chandra V R. Degradation mechanism for high-temperature sliding wear in surface-modified $\operatorname{In} 718$ superalloy. Cogent Eng 5(1): 1501864 (2018)

[13] He Q, Li A L, Qu W H, Zhang Y, Wang T, Kong L H. Investigation on friction and wear properties of hightemperature bearing steel 9Cr18Mo. Mater Res 21(3): e20170715 (2018)

[14] Jing X T, Lou B Z, Shen F S. Fatigue crack growth and crack closure behavior of the CrNiMo steels at negative stress ratio. In Proceedings of the 7th International Conference On Fracture (ICF7). Salama K, Ravi-chandar K, Taplin D M R, Rao P R, Eds. Amsterdam: Elsevier, 1989: $1187-1194$

[15]Grzesik W, Niesłony P, Habrat W, Sieniawski J, Laskowski P. Investigation of tool wear in the turning of Inconel 718 superalloy in terms of process performance and productivity enhancement. Tribol Int 118: 337-346 (2018)

[16] Liu W C, Yao M, Chen Z L, Wang S G. Niobium segregation in inconel 718. J Mater Sci 34(11): 2583-2586 (1999)

[17] Azadian S, Wei L Y, Warren R. Delta phase precipitation in Inconel 718. Mater Character 53(1): 7-16 (2004)

[18] Liang H Q, Zeng Y P, Zuo K H, Xia Y F, Yao D X, Yin J W. Mechanical properties and thermal conductivity of $\mathrm{Si}_{3} \mathrm{~N}_{4}$ ceramics with $\mathrm{YF}_{3}$ and $\mathrm{MgO}$ as sintering additives. Ceram Int 42(14): 15679-15686 (2016)

[19] Whitenton E P, Blau P J. A comparison of methods for determining wear volumes and surface parameters of spherically tipped sliders. Wear 124(3): 291-309 (1988)

[20] Varga M, Rojacz H, Winkelmann H, Mayer H, Badisch E. Wear reducing effects and temperature dependence of tribolayer formation in harsh environment. Tribol Int 65: 190-199 (2013)

[21] Sangwal K, Surowska B, Błaziak P. Analysis of the indentation size effect in the microhardness measurement of some cobalt-based alloys. Mater Chem Phys 77(2): 511-520 (2003)

[22] Petrík J, Palfy P. The influence of the load on the hardness. Metrol Meas Syst 18(2): 223-234 (2011)

[23] Guo E Y, Singh S S, Kaira C S, Meng X Y, Xu Y J, Luo L 
S, Wang M Y, Chawla N. Mechanical properties of microconstituents in $\mathrm{Nb}-\mathrm{Si}-\mathrm{Ti}$ alloy by micropillar compression and nanoindentation. Mater Sci Eng A 687: 99-106 (2017)

[24] Kalkhoran S M, Choi W B, Gouldstone A. Estimation of plastic anisotropy in $\mathrm{Ni}-5 \% \mathrm{Al}$ coatings via spherical indentation. Acta Mater 60: 803-810 (2012)

[25] Wang M Z, Wu J J, Wu H F, Zhang Z K, Fan H. A novel approach to estimate the plastic anisotropy of metallic materials using cross-sectional indentation applied to extruded magnesium alloy AZ31B. Materials 10(9): 1065 (2017)

[26] Knorovsky G A, Cieslak M J, Headley T J, Romig A D, Hammetter W F. INCONEL 718: A solidification diagram. Metall Trans A 20(10): 2149-2158 (1989)

[27] Burnett P J, Rickerby D S. The relationship between hardness and scratch adhession. Thin Solid Films 154(1-2): 403-416 (1987)

[28] Zhang D Y, Niu W, Cao X Y, Liu Z. Effect of standard heat treatment on the microstructure and mechanical properties of selective laser melting manufactured Inconel 718 superalloy. Mater Sci Eng: A 644: 32-40 (2015)

[29] Munagala V N V, Torgerson T B, Scharf T W, Chromik R R. High temperature friction and wear behavior of cold-sprayed Ti6Al4V and Ti6Al4V-TiC composite coatings. Wear 426-427: 357-369 (2019)

[30] Novak R, Polcar T. Tribological analysis of thin films by pin-on-disc: Evaluation of friction and wear measurement uncertainty. Tribol Int 74: 154-163 (2014)

[31] De Baets P, Strijckmans K, Van Peteghem A P. A comparative study of different wear measurement techniques applied to fretting wear of a spherical against a flat steel specimen. Tribotest 4(2): 129-143 (1997)

[32] Huang C M, Zou B, Liu Y N, Zhang S, Huang C Z, Li S S. Study on friction characterization and wear-resistance properties of $\mathrm{Si}_{3} \mathrm{~N}_{4}$ ceramic sliding against different hightemperature alloys. Ceram Int 42(15): 17210-17221 (2016)

[33] Stott F H, Wood G C. The influence of oxides on the friction and wear of alloys. Tribol Int 11(4): 211-218 (1978)

[34] Qu S G, Lai F Q, Wang G H, Yuan Z M, Li X Q, Guo H. Friction and wear behavior of $30 \mathrm{CrMnSiA}$ steel at elevated temperatures. J Mater Eng Perform 25(4): 1407-1415 (2016)

[35] Qiu M, Zhang Y Z, Zhu J, Luo X. The effect of dynamic frictional heating on the dry sliding behaviors of M2 steel against GCr15 steel. Wear 261(7-8): 767-772 (2006)

[36] Vasudev H, Thakur L, Bansal A, Singh H, Zafar S. High temperature oxidation and erosion behaviour of $\mathrm{HVOF}$ sprayed bi-layer Alloy-718/NiCrAlY coating. Surf Coat Technol 362: 366-380 (2019)

[37] Merz R, Brodyanski A, Kopnarski M. On the role of oxidation in tribological contacts under environmental conditions. Conf Papers Sci 2015: 515498 (2015)

[38] Berlin J. Analysis of boron with energy dispersive X-ray spectrometry: Advances in light element analysis with SDD technology. Imaging Microsc 20-21 (2011)

[39] Mutalib M A, Rahman M A, Othman M H D, Ismail A F, Jaafar J. Chapter 9-Scanning Electron Microscopy (SEM) and Energy-Dispersive X-Ray (EDX) spectroscopy. In Membrane Characterization. Hilal N, Ismail A F, Matsuura T, Oatley-Radcliffe D, Eds. Amsterdam: Elsevier, 2017: 161-179.

[40] Lohaus C, Steinert C, Brötz J, Klein A, Jaegermann W. Systematic investigation of the electronic structure of hematite thin films. Adv Mater Interfaces 4: 1700542 (2017)

[41] Dhoble S M, Kulkarni N S. Biosynthesis and characterization of different metal nanoparticles by using fungi. Sch Acad J Biosci 4(11): 1022-1031 (2016)

[42] Phadungdhitidhada S, Mangkorntong P, Choopun S, Mangkorntong N. Raman scattering and electrical conductivity of nitrogen implanted $\mathrm{MoO}_{3}$ whiskers. Ceram Int 34(4): 1121-1125 (2008)

[43] Hong H S. The role of atmospheres and lubricants in the oxidational wear of metals. Tribol Int 35(11): 725-729 (2002)

[44] Cai Z X, Li F M, Rong M C, Lin L P, Yao Q H, Huang Y P, Chen $\mathrm{X}$, Wang $\mathrm{X} \mathrm{R}$. Chapter 1-Introduction. In Novel Nanomaterials for Biomedical, Environmental and Energy Applications. Wang X R, Chen X, Eds. Amsterdam: Elsevier, 2019: 1-36.

[45] Torres H, Ripoll M R, Prakash B. Tribological behaviour of self-lubricating materials at high temperatures. Int Mater $\operatorname{Rev}$ 63(5): 309-340 (2018)

[46] Chen F Y, Feng Y, Shao H, Zhang X B, Chen J, Chen N N. Friction and wear behaviors of $\mathrm{Ag} / \mathrm{MoS}_{2} / \mathrm{G}$ composite in different atmospheres and at different temperatures. Tribol Lett 47(1): 139-148 (2012)

[47] Hamdani F. Improvement of the corrosion and oxidation resistance of Ni-based alloys by optimizing the chromium content. Ph.D Thesis. Senda (Japan): Tohoku Gakuin 
University, 2015.

[48] Tuzi S. Electron microscopy of oxide formed on nickel alloy $\mathrm{X}-750$ in simulated boiling water reactor environment. Ph.D Thesis. Goteborg (Sweden): Chalmers University of Technology, 2017.

[49] Radhakrishnan R, Oyama S T, Chen J G, Asakura K. Electron transfer effects in ozone decomposition on supported manganese oxide. J Phys Chem B 105(19): 4245-4253 (2001)

[50] Mougin J, Le Bihan T, Lucazeau G. High-pressure study of $\mathrm{Cr}_{2} \mathrm{O}_{3}$ obtained by high-temperature oxidation by X-ray diffraction and Raman spectroscopy. J Phys Chem Solids 62(3): 553-563 (2001)

[51] Trindade V, Krupp U, Wagenhuber E G, Christ H J. Oxidation mechanisms of Cr-containing steels and Ni-base alloys at high-temperatures-Part I: The different role of alloy grain boundaries. Mater Corros 56(11): 785-790 (2005)

[52] Ichimura H, Kawana A. High temperature oxidation of ion-plated CrN films. J Mater Res 9(1): 151-155 (1994)

[53] Li R, He D Y, Zhou Z, Wang Z J, Song X Y. Wear and high temperature oxidation behaviour of wire arc sprayed iron based coatings. Surface Eng 30(11): 784-790 (2014)

[54] Yilmaz C, Unal U. Effect of cerium doping on morphology and physical properties of $\alpha-\mathrm{Fe}_{2} \mathrm{O}_{3}$ films prepared by hydrothermal electrodeposition. ECS Trans 58(19): 55-63 (2014)

[55] Shui Y, Feng K Q, Zhang Y Y, Yan Z D. Influence of Mn on the iron-based friction material directly prepared by in situ carbothermic reaction from vanadium-bearing titanomagnetite concentrates. RSC Adv 8(64): 36503-36511 (2018)

[56] Salvaro D B, Silvério M, Binder C, Giacomelli R O, Klein A N, De Mello J D B. Genesis and stability of tribolayers in solid lubrication: Case of pair DLC-stainless steel. J Mater Res Technol 5(2): 136-143 (2016)

[57] Eyre T S. Wear characteristics of metals. Tribol Int 9(5): 203-212 (1976)

[58] Hardell J, Hernandez S, Mozgovoy S, Pelcastre L, Courbon C, Prakash B. Effect of oxide layers and near surface transformations on friction and wear during tool steel and boron steel interaction at high temperatures. Wear 330-331: 223-229 (2015)

[59] Yun J Y, Park D, Wang J P. A study on the oxidation behavior of nickel alloys at elevated temperatures. IOP Conf Series Mater Sci Eng 191(1): 012039 (2017)
[60] Wahl K J, Seitzman L E, Bolster R N, Singer I L, Peterson $\mathrm{M}$ B. Ion-beam deposited $\mathrm{Cu}-\mathrm{Mo}$ coatings as high temperature solid lubricants. Surface Coat Technol 89(3): 245-251 (1997)

[61] Holcomb G R, Tylczak J, Carney C. Oxidation of CoCrFeMnNi high entropy alloys. JOM 67(10): 2326-2339 (2015)

[62] Quinn T F J. Review of oxidational wear: Part I: The origins of oxidational wear. Tribol Int 16(5): 257-271 (1983)

[63] Quinn T F J. Review of oxidational wear part II: Recent developments and future trends in oxidational wear research. Tribol Int 16(6): 305-315 (1983)

[64] Singer I L. Solid lubricating films for extreme environments. MRS Online Proc Libr Arch 140: 215 (1988)

[65] Lancaster J K. The formation of surface films at the transition between mild and severe metallic wear. Proc Royal Soc London Series A. Math Phys Sci 273 (1355): 466-483 (1963)

[66] Pauschitz A, Roy M, Franek F. Mechanisms of sliding wear of metals and alloys at elevated temperatures. Tribol Int 41(7): 584-602 (2008)

[67] Stott F H, Lin D S, Wood G C. The structure and mechanism of formation of the 'glaze' oxide layers produced on nickel-based alloys during wear at high temperatures. Corros Sci 13(6): 455-469 (1973)

[68] Stott F H. The role of oxidation in the wear of alloys. Tribol Int 31(1-3): 61-71 (1998)

[69] Vashishtha N, Sapate S G. Abrasive wear maps for High Velocity Oxy Fuel (HVOF) sprayed WC-12Co and $\mathrm{Cr}_{3} \mathrm{C}_{2}-25 \mathrm{NiCr}$ coatings. Tribol Int 114: 290-305 (2017)

[70] Vashishtha N, Sapate S G, Gahlot J S, Bagde P. Effect of tribo-oxidation on friction and wear behaviour of HVOF sprayed WC-10Co-4Cr coating. Tribol Lett 66(2): 56 (2018)

[71] Trevisiol C, Jourani A, Bouvier S. Effect of hardness, microstructure, normal load and abrasive size on friction and on wear behaviour of 35NCD16 steel. Wear 388-389: 101-111 (2017)

[72] Bhatt A, Attia H, Vargas R, Thomson V. Wear mechanisms of WC coated and uncoated tools in finish turning of Inconel 718. Tribol Int 43(5-6): 1113-1121 (2010)

[73] Dorner-Reisel A, Schürer C, Müller E. The wear resistance of diamond-like carbon coated and uncoated Co28Cr6Mo knee prostheses. Diam Relat Mater 13(4-8): 823-827 (2004) 


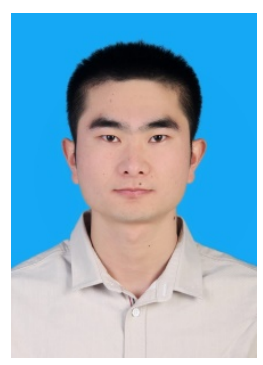

Liuyang BAI. He obtained his bachelor degree in School of Material Sciences and Engineering in 2018 from North Minzu University, Yinchuan, China.

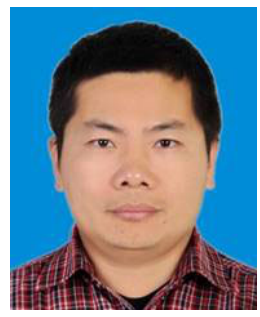

Shanhong WAN. He received his Ph.D. degree in the State Key Laboratory of Solid Lubrication at Lanzhou Institute of Chemical Physics, Chinese Academy of

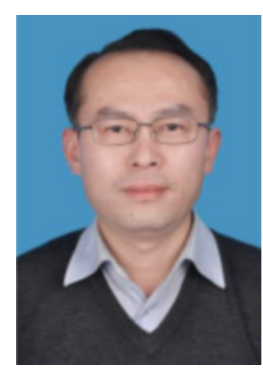

Gewen YI. He received his Ph.D. degree in the State Key Laboratory of Solid Lubrication at Lanzhou Institute of Chemical Physics,
Currently he is a M.S. student at the Lanzhou Institute of Chemical Physics, China. His current research is the tribological system of the metal/ceramic and ceramic/ ceramic.

Sciences, China, in 2010. His current position is a professor. His research areas cover hightemperature tribology of metal-ceramic composites and associated tribochemistry, and surface engineering.

Chinese Academy of Sciences, China, in 2007. His research focuses on tribological dynamics and microstructure characterization of solid lubricants subjected to a broad temperature range. 